\title{
An analytical model for gas overpressure in slug-driven explosions: Insights into Strombolian volcanic eruptions
}

\author{
Elisabetta Del Bello, ${ }^{1}$ Edward W. Llewellin, ${ }^{2}$ Jacopo Taddeucci, ${ }^{1}$ Piergiorgio Scarlato, ${ }^{1}$ \\ and Steve J. Lane ${ }^{3}$ \\ Received 18 August 2011; revised 9 December 2011; accepted 11 December 2011; published 10 February 2012.
}

[1] Strombolian eruptions, common at basaltic volcanoes, are mildly explosive events that are driven by a large bubble of magmatic gas (a slug) rising up the conduit and bursting at the surface. Gas overpressure within the bursting slug governs explosion dynamics and vigor and is the main factor controlling associated acoustic and seismic signals. We present a theoretical investigation of slug overpressure based on magma-static and geometric considerations and develop a set of equations that can be used to calculate the overpressure in a slug when it bursts, slug length at burst, and the depth at which the burst process begins. We find that burst overpressure is controlled by two dimensionless parameters: $V^{\prime}$, which represents the amount of gas in the slug, and $A^{\prime}$, which represents the thickness of the film of magma that falls around the rising slug. Burst overpressure increases nonlinearly as $V^{\prime}$ and $A^{\prime}$ increase. We consider two eruptive scenarios: (1) the "standard model," in which magma remains confined to the vent during slug expansion, and (2) the "overflow model," in which slug expansion is associated with lava effusion, as occasionally observed in the field. We find that slug overpressure is higher for the overflow model by a factor of 1.2-2.4. Applying our model to typical Strombolian eruptions at Stromboli, we find that the transition from passive degassing to explosive bursting occurs for slugs with volume $>24-230 \mathrm{~m}^{3}$, depending on magma viscosity and conduit diameter, and that at burst, a typical Strombolian slug (with a volume of $100-1000 \mathrm{~m}^{3}$ ) has an internal gas pressure of 1-5 bars and a length of 13-120 m. We compare model predictions with field data from Stromboli for low-energy "puffers," mildly explosive Strombolian eruptions, and the violently explosive 5 April 2003 paroxysm. We find that model predictions are consistent with field observations across this broad spectrum of eruptive styles, suggesting a common slug-driven mechanism; we propose that paroxysms are driven by unusually large slugs (large $V^{\prime}$ ).

Citation: Del Bello, E., E. W. Llewellin, J. Taddeucci, P. Scarlato, and S. J. Lane (2012), An analytical model for gas overpressure in slug-driven explosions: Insights into Strombolian volcanic eruptions, J. Geophys. Res., 117, B02206, doi:10.1029/ 2011JB008747.

\section{Introduction}

[2] Gas overpressure is the driving force of explosive volcanic activity and is one of the main sources of associated geophysical signals (mainly seismic and acoustic; see, for example, Chouet [2003] and Vergniolle et al. [1996] for an extensive treatment). Weak, impulsive Strombolian activity is thought to be caused by the explosive liberation of pressurized pockets of gas (slugs) that have risen through stagnant low-viscosity magma [e.g., Blackburn et al., 1976; Parfitt, 2004; Houghton and Gonnermann, 2008, and references therein]. Here we present an analytical model

\footnotetext{
${ }^{1}$ Department of Seismology and Tectonophysics, Istituto Nazionale $\mathrm{d}$ Geofisica e Vulcanologia, Rome, Italy.

${ }^{2}$ Department of Earth Sciences, Durham University, Durham, UK.

${ }^{3}$ Lancaster Environment Centre, Lancaster University, Lancaster, UK.

Copyright 2012 by the American Geophysical Union. 0148-0227/12/2011JB008747
}

which allows the minimum overpressure of such exploding gas slugs to be estimated.

[3] Low-viscosity magmatic systems may exhibit a variety of eruption styles, ranging from passive degassing through lava fountaining and up to Plinian eruptions [Parfitt and Wilson, 1995; Houghton and Gonnermann, 2008]. Such variations in intensity and style often occur within a short time span and have been explained in terms of either outgassing processes, i.e., how exsolved gas separates from the magma [Parfitt, 2004; Houghton and Gonnermann, 2008; Namiki and Manga, 2008], or variations in the mechanicalrheological properties of magma in the shallow conduit [Taddeucci et al., 2004a, 2004b; Valentine et al., 2005; Andronico et al., 2009; Cimarelli et al., 2010]. The discrete, often jet-like, bursting of meter-sized, conduit-filling gas bubbles at the surface of a column of magma, commonly defined as Strombolian activity, has been widely studied at Stromboli [Chouet et al., 1974; Blackburn et al., 1976; Rosi et al., 2000] and at several other persistently active 
volcanoes with low-viscosity magma, such as Erebus, Antarctica [e.g., Jones et al., 2008; De Lauro et al., 2009], Halema 'uma 'u vent [e.g., Chouet et al., 2010] and $\mathrm{Pu}$ 'u 'Ō'ō crater at Kīlauea, Hawai'i [e.g., Edmonds and Gerlach, 2007], and Nyiragongo, Democratic Republic of Congo [Sawyer et al., 2008]. These studies generally conclude that Strombolian activity occurs when overpressured gas, transported as discrete pockets or slugs, disrupts the surface of an almost stagnant magma column, ejecting magma fragments as pyroclasts.

[4] Gas slugs are believed to form by coalescence of smaller bubbles at depth, either by differential ascent rate of gas with respect to the surrounding magma [Parfitt and Wilson, 1995; Parfitt, 2004] or by accumulation and collapse of a foam layer at geometrical discontinuities within the plumbing system [Vergniolle and Jaupart, 1986; Jaupart and Vergniolle, 1988, 1989]. In either case, once the amount of gas has reached some critical value, a slug decouples from the magma and rises as a separate phase, potentially reaching the surface with a pressure significantly higher than atmospheric (i.e., with an overpressure). The density and viscosity ratios between the surrounding magma and the gas in the slugs are such that the composition of the volatile phase can be neglected [James et al., 2008].

[5] Gas overpressure is the key parameter in determining explosion vigor of Strombolian eruptions and the nature of associated hazards such as the range of ballistically transported volcanic bombs [e.g., McGetchin and Chouet, 1979; Self et al., 1979; Wilson, 1980; Alatorre-Ibargüengoitia et al., 2010; Vidal et al., 2010]. Overpressure has been determined from estimates of the initial velocity of gaspyroclast mixtures [Blackburn et al., 1976], from gas/ash velocity derived from thermal imagery [Ripepe and Harris, 2008], and from synthetic oscillating bubble waveforms [Vergniolle and Brandeis, 1996; Ripepe and Marchetti, 2002]. Attention has also been paid to the role of overpressured gas slugs as a source of infrasonic and seismic signals at Stromboli [e.g., Vergniolle and Brandeis, 1996; Ripepe and Gordeev, 1999; Ripepe and Marchetti, 2002; Vergniolle et al., 2004; Ripepe and Harris, 2008], which has permitted quantitative determination of overpressure during explosive eruptions.

[6] Infrasound and other geophysical signals are generated by changes in the pressure distribution within the conduit during the ascent and burst of gas slugs. The intensity of the pressure change is strongly dependent on the size of the slug and on the viscosity of the conduit-filling magma [James et al., 2004, 2006; Chouet et al., 2003; Vergniolle and Ripepe 2008], and several studies yield constraints on the interpretation of geophysical signals using models that rely on geometrical parameters of the slugs (size, radius, and thickness of the surrounding magma layer). These parameters have been inferred from seismic [Chouet et al. 2003; O'Brien and Bean, 2008], acoustic [Vergniolle and Brandeis, 1996], thermal [Harris and Ripepe, 2007a], and Doppler [Gerst et al., 2008] measurements and estimated from visual observation [Chouet et al. 1974; Vergniolle et al., 1996; 2004] and the maximum size of ejecta [Blackburn et al., 1976; Wilson, 1980].

[7] The degree of gas overpressure that a slug acquires prior to bursting depends on the balance of the magmastatic, viscous, and inertial forces acting on the slug during its ascent of the conduit. Previous analytical [Vergniolle and Brandeis, 1994; Seyfried and Freundt, 2000; James et al., 2008, 2009], numerical [D'Auria, 2006; James et al., 2008], and laboratory models [Jaupart and Vergniolle, 1988; Seyfried and Freundt, 2000; James et al., 2004, 2006, 2008] have explored in detail the formation, ascent, and expansion of slugs in vertical and inclined conduits. These works have focused largely on slug formation and motion rather than on explosion. However, James et al. [2009] qualitatively correlated overpressure in the slug with different regimes of "burst vigor," linking the magnitude of the measurable geophysical effects of overpressure, e.g., pressure transients and acoustic signals, to the surface style of an eruption.

[8] In this paper we propose a new solution to the problem of determining volcanic gas overpressure during Strombolian eruptions. We adopt and expand the analysis of James et al. [2009] to build a simple analytical model that describes the conditions under which a gas slug rising in a cylindrical conduit becomes overpressured and that predicts the overpressure when the slug bursts. Using this model, we identify and quantitatively explore two key parameters that control pressure inside a slug at the time of explosion: (1) the amount of gas in the slug and (2) the thickness of the liquid film draining down the conduit around the rising slug. On the basis of analogue experimental data [Llewellin et al., 2011] we also develop a new framework for estimating relevant geometrical parameters for volcanic slugs over the range of plausible conduit conditions. We then apply our model to predict the overpressure of Strombolian eruptions using appropriate volcano-scale parameters. Model outputs are validated against previously published estimates of bursting overpressure derived from a broad data set of eruptions at Stromboli. Finally, we discuss whether the range of volcanic eruptions observed at Stromboli can be explained in terms of the ascent and burst of gas slugs.

\section{Eruptions at Stromboli}

[9] The current volcanic activity at Stromboli has persisted, without a significant break or change in style, for at least the last 1300 years [Rosi et al., 2000]. Its persistent state of activity, usually classified as "normal" [Barberi et al., 1993], is characterized by intermittent, mildly explosive activity and continuous degassing, occurring simultaneously at multiple craters, on a crater terrace, located at $\sim 800 \mathrm{~m}$ above sea level (Figures $1 \mathrm{a}$ and $1 \mathrm{~b}$ ). Two main types of explosions characterize normal activity: (1) "puffers," defined as nonpassive degassing phenomena, where the gas is erupted with an overpressure but is not associated with ejection of pyroclasts (Figure 1a), and (2) "Strombolian" activity, where the explosive liberation of gas is accompanied by the ejection of disrupted magma fragments (Figure 1b). Normal activity is occasionally interrupted by more violent "major explosions" and "paroxysms" (Figure 1c) and by lava flow activity [Barberi et al., 1993]. During normal activity, the rise and bursting of large gas slugs at the surface of the magma column cause recurring explosive events, which last tens of seconds and have a return interval of a few minutes (5-20 events per hour [Ripepe et al., 2002; Chouet et al., 2003, and references therein]). These explosions result in the emission of jets of 
gas and incandescent magma fragments to heights of 100 $200 \mathrm{~m}$ above the vents (Figure 1b).

[10] The depth of formation of gas slugs at Stromboli has been estimated from the composition of erupted gases. The pressure dependence of gas solubility in the melt varies with gas species [see e.g., Anderson, 1995; Bottinga and Javoy, 1989, 1990, 1991]; consequently, the ratio of the abun-
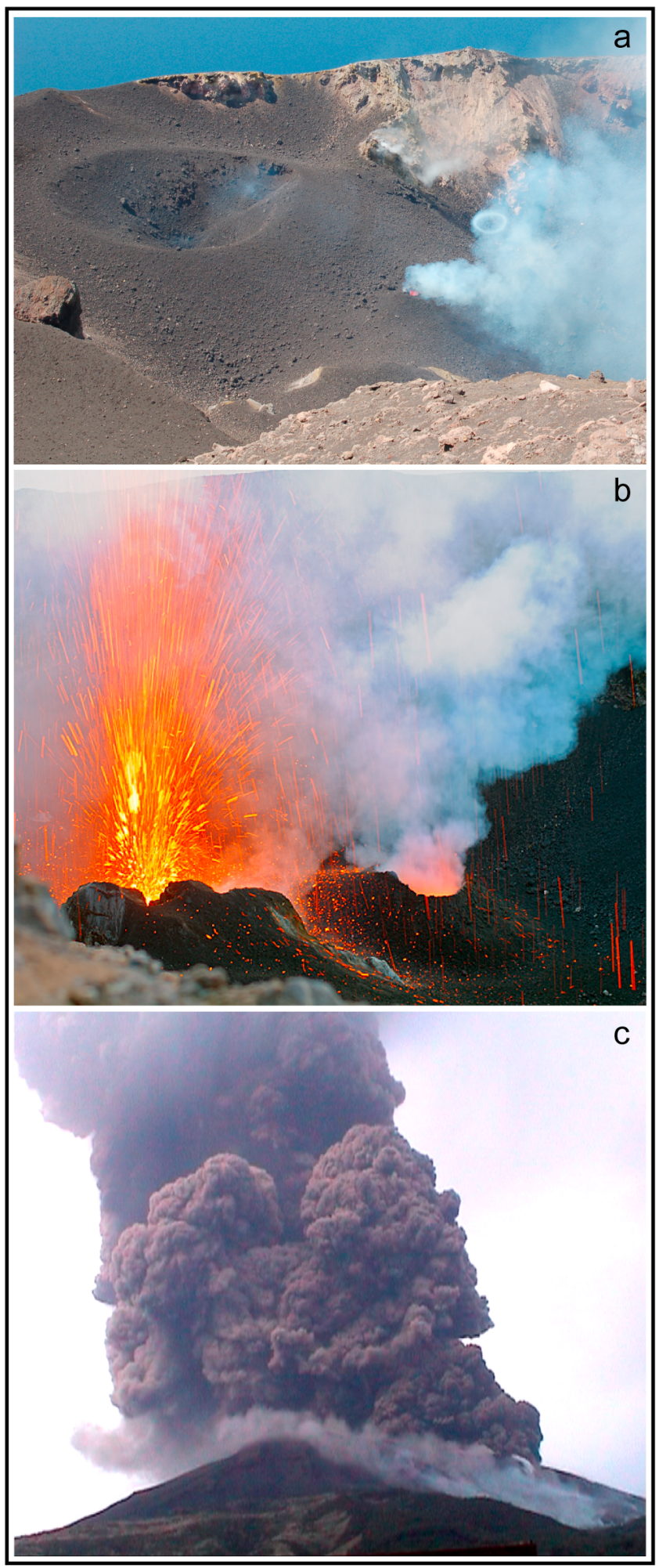

dances of the various gas species erupted during a slug burst event indicates the depth at which the gas in the slug was in equilibrium with the melt. At Stromboli, Open Path Fourier Transform Infrared (OP-FTIR) spectroscopy of erupting volatiles reveals that the gases erupted during Strombolian explosions have mean $\mathrm{CO}_{2} / \mathrm{SO}_{2}, \mathrm{SO}_{2} / \mathrm{HCl}$, and $\mathrm{CO} / \mathrm{CO}_{2}$ ratios that are 3-5 times higher than those measured during continuous passive degassing [Burton et al., 2007a]. This indicates that Strombolian eruptions are driven by $\mathrm{CO}_{2}$-rich, water-poor gas slugs in equilibrium with a hot magma source $\left(\sim 1100^{\circ} \mathrm{C}\right)$ under confining pressures of $\sim 70-80 \mathrm{MPa}$ (corresponding to a depth range of $\sim 0.8-2.7 \mathrm{~km}$ ). This depth corresponds to a region where structural discontinuities in the crust [Chouet et al., 2008] and differential bubble rise speed may promote bubble coalescence and separation from the melt.

[11] Paroxysms are characterized by violent, higher-magnitude explosions that occasionally interrupt normal Strombolian activity [Barberi et al., 1993; Rosi et al., 2006; Bertagnini et al., 2008]. There have been 25 paroxysmal events in the last 2 centuries [Barberi et al., 1993]. Such events generate plumes up to $4 \mathrm{~km}$ high and produce greater volumes of ejecta than normal activity [Rosi et al., 2006; Barberi et al., 2009].

[12] There are two leading models to explain the origin of paroxysms: (1) a "gas trigger" model [Allard, 2010] and (2) a "magma trigger" model [Métrich et al., 2010]. The gas trigger model proposes that highly energetic, paroxysmal eruptions at Stromboli are also caused by gas slugs but that they originate from much greater depths than for normal activity. The gas slugs driving paroxysmal eruptions show even greater enrichment in $\mathrm{CO}_{2}$ with respect to normal Strombolian eruptions, corresponding to equilibrium with a magma source more than $4 \mathrm{~km}$ deep [Allard, 2010; Aiuppa et al., 2010]. This has been proposed by Allard et al. [2008], Allard [2010], and Aiuppa et al. [2010] on the basis of geochemical composition of the gas emitted during 5 April 2003 and 15 March 2007 paroxysms, respectively, and by Pino et al. [2011] on the basis of geochemical data and precursory seismic signals for the April 2003 explosion. The contrasting "magma trigger" model hypothesizes that paroxysms are triggered by the rapid ascent (in a few hours or days) of pockets of volatile-rich basaltic magma from a 7-10 km deep reservoir; this model was proposed by Bertagnini et al. [2003] and Métrich et al. [2010] on the

Figure 1. Main eruption types at Stromboli. (a) A panoramic view of part of Stromboli crater terrace. "Gas puffing" is taking place at a glowing vent on the right-hand side on the image; note the "smoke ring" (picture taken in May 2009, courtesy of M. Rosi). (b) A typical Strombolian explosion from a vent (on the left-hand side) with simultaneous degassing at an adjacent vent (on the right-hand side) in the SW crater (picture taken in June 2008, copyright M. Fulle, reprinted with permission). Vents diameters range from approximately 2 to $5 \mathrm{~m}$. (c) A still image of the 5 April 2003 paroxysmal explosive event captured $\sim 1 \mathrm{~s}$ after the beginning of the eruption (09:13 LT, photograph taken by P. Scarlato). Vertical height of the picture is $\sim 2 \mathrm{~km}$. 


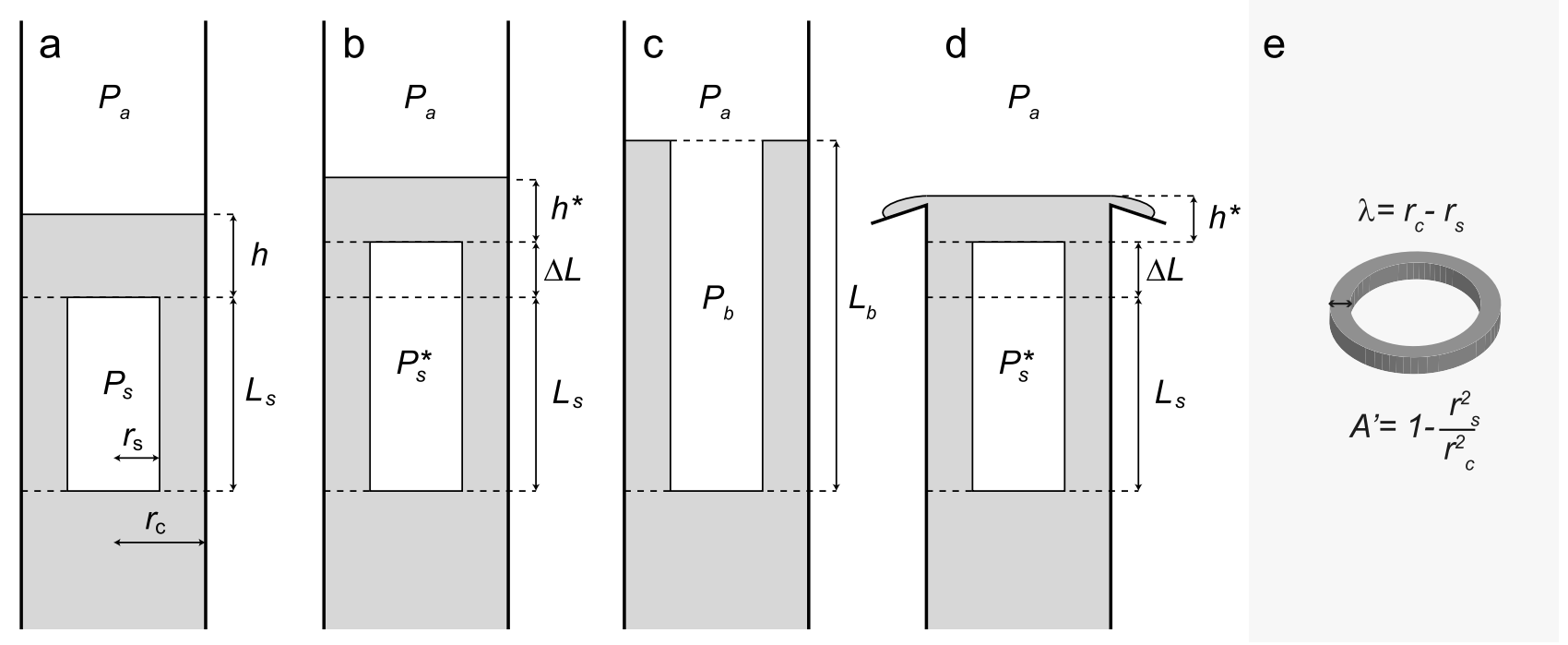

Figure 2. Theoretical model of a cylindrical slug of radius $r_{s}$ and length $L_{s}$ bursting at the top of an idealized conduit of radius $r_{c}$. (a) Initially, gas pressure in the slug $\left(P_{s}\right)$ is in equilibrium with the magmastatic $(\rho \mathrm{g} h)$ plus atmospheric pressure $\left(P_{a}\right)$ as the slug rises. (b) When a perturbation causes the slug to lengthen by a small amount $(\Delta L)$ the magma-static head decreases to $h^{*}\left(h^{*}<h\right)$ and both the pressure within the slug (now $P^{*}$ ) and the magma-static pressure $\left(\rho \mathrm{g} h^{*}\right)$ decrease. (c) If magma-static pressure drops below the slug pressure, the perturbation grows, causing the slug to burst with a pressure $P_{b}$ and length $L_{b}$. (d) If magma is allowed to erupt from the conduit during slug ascent (overflow model, section 3.2), the height of the column of magma above the slug during perturbation is smaller than in case in Figure 2b. (e) Cross section of a conduit occupied by a gas slug, illustrating schematically the thickness $(\lambda)$ of the liquid film and the dimensionless parameter $A^{\prime}$.

basis of the texture and chemistry of pyroclasts. A third model has recently been proposed by Calvari et al. [2011], who have suggested that intense effusive activity and associated magma-static load removal may trigger paroxysmal eruptions by decompression of the plumbing system.

\section{Slug Overpressure Model}

[13] In this section, we develop two models for the development of overpressure in a gas slug during its ascent of a magma-filled conduit. The main aim is to quantify the pressure inside the slug at the moment of burst, when the gas is liberated to the atmosphere. In the first model, the "standard model," we assume that the magma is confined to the conduit and does not overflow during the slug's ascent; this is consistent with observations of normal Strombolian activity. In the second model, the "overflow model," we assume that the expansion of the slug during ascent causes the magma above it to overflow; this is consistent with observations of paroxysmal activity.

\subsection{Development of Slug Overpressure in the Absence of Magma Effusion (Standard Model)}

[14] To quantify the pressure evolution inside a rising slug when magma is confined to the conduit, we develop a model that builds on the "static pressure limit approach" developed by James et al. [2009, sections 2 and 3]. In their model, the rising slug is treated as a cylinder of length $L_{s}$ and constant radius $r_{s}$, rising along the axis of a cylindrical pipe of radius $r_{c}$ (Figure 2). As the slug ascends, it grows in response to the decrease in the magma-static head. Inertial and viscous forces acting on slug expansion at the conduit scale are neglected in the formulation of the model.

[15] James et al. [2009] have demonstrated that although simplified, the static model is in good agreement with data from experiments involving only relatively modest slug expansion, implying that for these conditions, the contribution of viscous and inertial effects on dynamic expansion can be neglected. For larger, more rapid slug expansion, viscous and inertial effects become more important and act to increase slug overpressure; in this case our model can be considered a lower limit for overpressure at burst.

[16] As the slug rises from depth (Figure 2a), the pressure $P_{s}$ of the gas within the slug is in equilibrium with the magma-static pressure $P_{h}$ due to the column of liquid above the slug, which is given by

$$
P_{h}=\rho g h+P_{a},
$$

where $\rho$ is the magma density, $g$ is the gravitational acceleration, $h$ is the height of the column of liquid above the slug, and $P_{a}$ is the ambient pressure at the top of the conduit. As the slug rises, it expands in response to decreasing $P_{h}$. Since thermal effects and nonideal gas behavior are shown to be secondary processes and can be neglected [Seyfried and Freundt, 2000; James et al., 2008], we assume that the gas within the slug behaves isothermally; hence, $P_{s} L_{s}=$ const. It is useful to define a reference slug length, $L_{a}$, which is the length that the slug would have at atmospheric pressure $P_{a}$; hence,

$$
P_{s} L_{s}=P_{a} L_{a} .
$$


The mass of gas in the slug is assumed to be constant (i.e., there is no diffusion of volatiles from the surrounding melt and no coalescence with other bubbles during ascent, as supported by gas-melt chemistry data [Burton et al., 2007a; Allard, 2010]); hence, the size of the slug can be related to the number of moles of gas $n$ that it contains, assuming the ideal gas law:

$$
P_{a} L_{a} \pi r_{s}^{2}=n R T,
$$

where $R$ is the ideal gas constant and $T$ is the absolute temperature of the gas.

[17] James et al. [2009] consider the stability of the equilibrium between the pressure in the slug and the magmastatic pressure above the slug in response to a perturbation which increases the slug length by a small amount $\Delta L$, during which the base of the slug is stationary (Figure $2 b$ ). The perturbation causes a change in both the pressure within the slug and the magma-static pressure above the slug. The pressure within the slug decreases according to equation (2); hence, the perturbed pressure in the slug $P_{s}^{*}$ becomes

$$
P_{s}^{*}=\frac{P_{a} L_{a}}{L_{s}+\Delta L} .
$$

The perturbation also causes magma to flow from the head region into the falling film around the slug. Conservation of magma volume gives the perturbed height of the magma column above the slug $h^{*} r_{c}^{2}=h r_{c}^{2}-\Delta L\left(r_{c}^{2}-r_{s}^{2}\right)$; hence, the perturbed magma-static pressure above the slug $p_{h}^{*}$ also decreases, becoming (from equation (1))

$$
P_{h}^{*}=\rho g\left(h-A^{\prime} \Delta L\right)+P_{a},
$$

where $A^{\prime}$ is the fraction of the cross-sectional area of the conduit that is occupied by the falling film in the slug region (Figure 2e):

$$
A^{\prime}=1-\frac{r_{s}^{2}}{r_{c}^{2}} .
$$

The competition between these two pressure changes determines whether the perturbation grows $\left(P_{s}^{*}>P_{h}^{*}\right)$ or decays $\left(P_{h}^{*}>P_{s}^{*}\right)$. If, in the limit $\Delta L \rightarrow 0$, the perturbation decays (i.e., the decrease in slug pressure is larger than the decrease in magma-static pressure), then the slug is stable. Conversely, for an unstable slug, the slug pressure decrease is not balanced by the decreasing magma-static pressure; hence, the perturbation grows, and the slug continues to lengthen until all the liquid above it has moved to the annulus around the growing slug, at which point the slug has burst (Figure 2c). Note that in this context, "unstable" refers to the loss of equilibrium between magma-static pressure and slug pressure and does not imply that the slug will break up.

[18] James et al. [2009] demonstrate that some slugs rise to the surface without becoming unstable, while others become unstable at a finite depth $h$. By considering the limiting case $P_{s}^{*}=P_{h}^{*}$, they find that such a slug becomes unstable when its pressure drops below a limiting pressure $\left(P_{s \text { lim }}\right)$ given by

$$
P_{\text {slim }} \equiv \sqrt{\rho g A^{\prime} P_{a} L_{a}} .
$$

By setting $P_{s \text { lim }}=P_{a}$ we can determine the maximum size for a slug that can rise to the surface without becoming unstable, expressed as its equivalent length at atmospheric pressure:

$$
L_{\text {alim }}=\frac{P_{a}}{\rho g A^{\prime}} .
$$

If $L_{a} \leq L_{a}$ lim , then the slug is sufficiently small that the equilibrium $P_{s}=P_{h}$ is maintained throughout the slug's journey to the surface, where it releases its gas passively. If, by contrast, $L_{a}>L_{a}$ lim , then the slug will become unstable before it reaches the surface and will burst with an overpressure. We suggest that equation (8) represents a more intuitive criterion for the transition between passive degassing and Strombolian eruption than that presented by James et al. [2009].

[19] The depth at which a slug becomes unstable $\left(h_{\text {lim }}\right)$ can be determined by setting $P_{s}>S_{s}$ lim in equation (1), yielding

$$
h_{\text {lim }}=\frac{P_{\text {slim }}-P_{a}}{\rho g},
$$

which is equivalent to equation (12) of James et al. [2009]. We define the beginning of the burst process, for an unstable slug, as the point when it reaches depth $h_{\text {lim }}$. The burst process is completed when the magma-static head approaches zero (i.e., when the slug nose reaches the surface); at this point, all of the liquid that was above the slug when it became unstable has moved into the annular falling film around the slug. We assume that the velocity of the slug nose is rapid during the burst process compared with the velocity of the slug base during burst; hence, we treat the slug base as stationary throughout the burst process (Figure 2c). Conservation of liquid volume in the system dictates that the length of the slug at burst is given by $L_{b}=L_{s}$ lim $+h_{\text {lim }} / A^{\prime}$, where $L_{s}$ lim is the length of the slug when it becomes unstable; hence, the pressure in the slug when the slug nose reaches the magma surface is given by

$$
P_{b}=\frac{A^{\prime} P_{a} L_{a}}{A^{\prime} L_{s} \lim +h_{\text {lim }}}=\frac{\rho g A^{\prime} P_{a} L_{a}}{2 \sqrt{\rho g A^{\prime} P_{a} L_{a}}-P_{a}} .
$$

\subsection{Development of Slug Overpressure During Effusion of Lava (Overflow Model)}

[20] The standard model outlined in section 3.1 follows the assumption of James et al. [2009] that the magma above the slug remains confined to the volcanic conduit as it is pushed upward by the expanding slug. This is consistent with observations of normal Strombolian eruptions, for which very little magma is erupted (Chouet et al. [1974] report a volume ratio of erupted gas to erupted magma of $10^{4}-10^{5}$ ). It also implies that the magma surface must be sufficiently far below the vent in the interval between slug arrivals, so that magma does not overflow during slug ascent and burst. This is supported at Stromboli by the delay time between seismic and acoustic signals recorded during normal explosions, which indicates that the surface of an approximately stagnant magma column resides at a depth of around 100-200 m below the craters [Ripepe et al., 2002, and references therein]. 


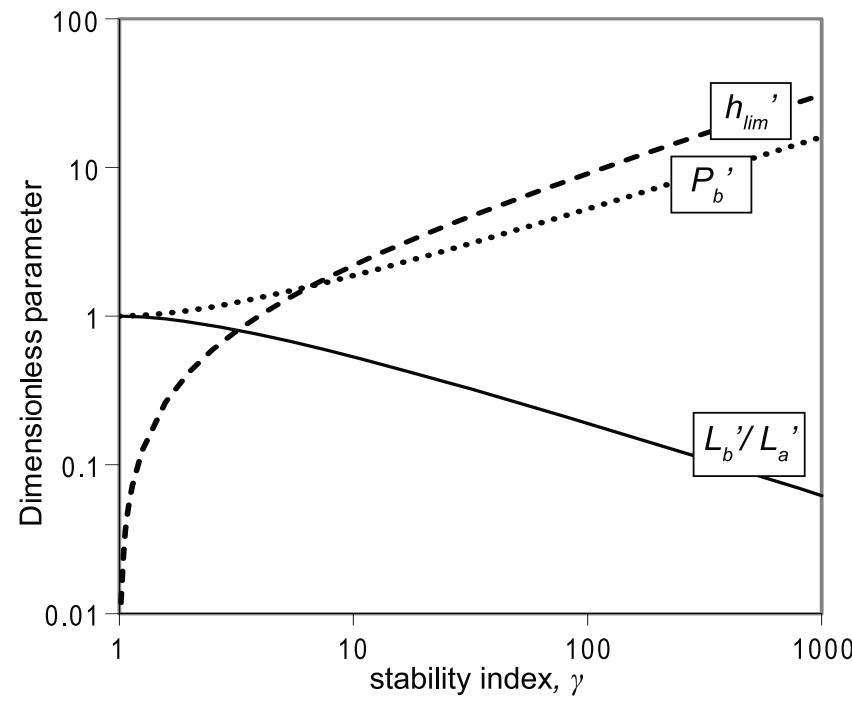

Figure 3. Dimensionless depth of burst onset ( $h_{\text {lim }}^{\prime}$, equation (15), dashed line), dimensionless burst overpressure ( $P_{b}^{\prime}$, equation (16), dotted line), and ratio of slug expansion $\left(L_{b}^{\prime} / L_{a}^{\prime}\right.$, equation (17), solid line) as functions of the dimensionless stability index ( $\gamma$, equation (13)), which describes how much bigger a slug is than the smallest slug that will burst with an overpressure.

[21] The assumption is not, however, consistent with some observations of paroxysmal eruptions. Calvari et al. [2011] collate observational data from paroxysmal eruptions at Stromboli in 2003 and 2007 and conclude that paroxysmal eruptions may occur during periods of lava effusion, as a consequence of magma depressurization. We note that the hypothesis of Calvari et al. is based on a small number of recent events and that it is possible that paroxysmal eruptions may have occurred during periods without lava effusion. However, simultaneous effusive/explosive activity is not an uncommon process at basaltic volcanoes and has been observed, e.g., at Stromboli crater terrace in November 2010 and during 2001 and 2002-2003 scoria cone-building eruptions at Etna. In this case, the standard model must be modified to account for magma overflow during slug ascent. Figure $2 \mathrm{~d}$ illustrates the effect of perturbation on a slug ascending a conduit from which magma is effusing. Because of the overflow of magma during perturbation, the perturbed height of the magma column above the slug is smaller than is the case for the standard model; consequently, equation (5) becomes

$$
P_{h}^{*}=\rho g(h-\Delta L)+P_{a} .
$$

This is identical to equation (5) except that $A^{\prime}$ no longer appears because the volume of magma in the head region above the slug is no longer conserved owing to overflow. This modification propagates through the analysis presented in section 3.1. We term this case the overflow model to distinguish it from the standard model set out in section 3.1. New equations for $P_{s \text { lim }}, L_{a \text { lim }}$, and $P_{b}$ relevant to the overflow case can be recovered by removing $A^{\prime}$ from equations (7), (8), and (10), respectively.

\subsection{Model Nondimensionalization}

[22] To nondimensionalize the above set of equations (equations (1)-(11)), we choose $P_{a}$ as the characteristic pressure and $P_{a} / \rho \mathrm{g}$ as the characteristic length scale. The slug length can then be represented as a dimensionless quantity (indicated by a tick):

$$
L_{a}^{\prime}=L_{a} \frac{\rho g}{P_{a}}
$$

Other quantities are nondimensionalized as follows:

$$
P_{\text {slim }}^{\prime}=\frac{P_{\text {slim }}}{P_{a}}, h_{\text {lim }}^{\prime}=h_{\text {lim }} \frac{\rho g}{P_{a}}, P_{b}^{\prime}=\frac{P_{b}}{P_{a}}, L_{b}^{\prime}=L_{b} \frac{\rho g}{P_{a}},
$$

where $P_{s}^{\prime} \lim$ is the same as $P_{s}^{*} \lim$ in equation (13) and Figure 5 of James et al. [2009]. From equation (8), we can see that the product of $A^{\prime}$ and $L_{a}^{\prime}$ gives the ratio of the slug length to the critical slug length $L_{a}$ lim (i.e., it describes how much bigger this slug is than the smallest slug that will burst with an overpressure); we call this ratio the stability index, $\gamma$ :

$$
\gamma=A^{\prime} L_{a}^{\prime}=\frac{L_{a}}{L_{\text {alim }}} .
$$

Applying the nondimensionalization to the system of equations developed in section 3.1 reveals that $\gamma$ is the key parameter describing the burst process. The slug pressure at the onset of bursting (equation (7)) becomes

$$
P_{\text {slim }}^{\prime}=\sqrt{\gamma}
$$

the depth at which the burst process begins (equation (9)) becomes (for $\gamma>1$ )

$$
h_{\text {lim }}^{\prime}=\sqrt{\gamma}-1
$$

and the slug pressure at burst (equation (10)) becomes (for $\gamma>1$ )

$$
P_{b}^{\prime}=\frac{\gamma}{2 \sqrt{\gamma}-1}
$$

Since $P_{b}^{\prime} L_{b}^{\prime}=P_{a}^{\prime} L_{a}^{\prime}$, where $P_{a}^{\prime}>1$ and the dimensionless slug length at burst is $L_{b}^{\prime}=L_{b}\left(\rho g / P_{a}\right)$, we can also write

$$
\frac{L_{b}^{\prime}}{L_{a}^{\prime}}=\frac{1}{P_{b}^{\prime}}=\frac{2 \sqrt{\gamma}-1}{\gamma}
$$

this latter parameter will be used in section 5 to determine the slug length at burst. The burst process can, therefore, be described entirely by the parameter $\gamma$. If $\gamma \leq 1$, the slug is stable throughout its journey to the surface. Note that for stable slugs, equation (15) gives negative values for burst depth and neither equation (15) nor equation (16) is physically meaningful. If $\gamma>1$, the slug becomes unstable at a depth indicated by equation (15) and subsequently bursts with an overpressure as given by equation (16), with a final length expressed by equation (17). The larger the value of $\gamma$, the greater the burst overpressure; as a corollary, the slug expands less during the burst process for larger $\gamma$. This nondimensionalization is valid for both the standard (section 3.1) and the overflow models (section 3.2); in the overflow case, $A^{\prime}$ does not appear in equation (8); hence (from equation (13)), $\gamma=L_{a}^{\prime}$.

\subsection{Model Behavior}

[23] The dependence of the depth of burst onset, the burst overpressure, and the length of the slug at burst on the stability index $\gamma$ is shown in Figure 3. For values of $\gamma<1$, the 


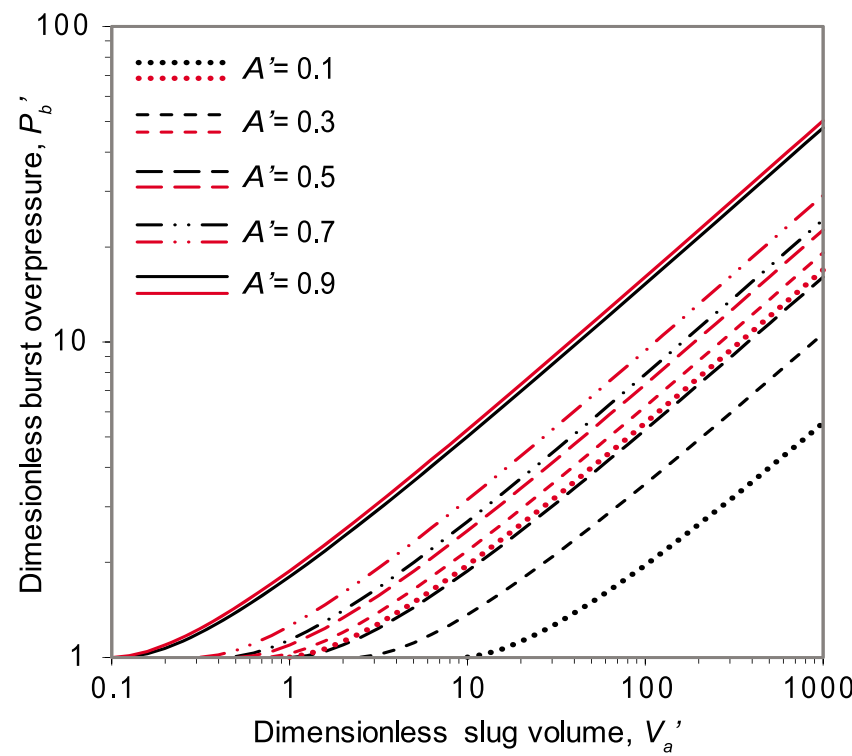

Figure 4. Dimensionless burst overpressure $P_{b}^{\prime}$ as a functio$\mathrm{n}$ of dimensionless slug volume $V_{a}^{\prime}$ (equations (18) and (19)) for various values of parameter $A^{\prime}$ (equation (6)), which represents the fraction of the conduit's cross-sectional area occupied by the liquid film draining around the slug (larger $A^{\prime}$ represents a thicker film). Black and red curves represent model outputs for the standard model (section 3.1) and the overflow model (section 3.2).

pressure in the slug never exceeds local magma-static pressure, and the slug reaches the surface in equilibrium with atmospheric pressure. For large values of $\gamma$ (i.e., when the slug is much larger than the critical slug size, $L_{a} \gg L_{a}$ lim), the slug burst overpressure is approximately given by $P_{b}^{\prime} \approx$ $\sqrt{\gamma} / 2$, and the length of the slug at burst is given by the ratio $L_{b}^{\prime} / L_{a}^{\prime} \approx 2 / \sqrt{\gamma}$.

[24] In order to set the above analysis in a more realistic volcano-monitoring context, we demonstrate how the value of the stability index $\gamma$ (equation (13)) may be determined from field observations. Equation (13) relates the stability index to the slug length; however, the volume of gas released by a slug burst $V_{a}$ is a more practical quantity since it may be determined by various established monitoring techniques (see section 4.3). We define the dimensionless slug volume $V_{a}^{\prime}$ as the volume of an erupted gas slug $V_{a}$, normalized by the characteristic volume $\pi r_{c}^{2} P_{a} / \rho g$ (which is the product of the cross-sectional area of the conduit and the characteristic length scale):

$$
V_{a}^{\prime}=V_{a} \frac{\rho g}{\pi r_{c}^{2} P_{a}} .
$$

From equations (12) and (18) and noting that $V_{a}=L_{a} \pi r_{s}^{2}$ we find

$$
V_{a}^{\prime}=\left(1-A^{\prime}\right) L_{a}^{\prime}
$$

This relationship between the dimensionless length and volume of the slug applies to both the standard model and the overflow model; that is, $A^{\prime}$ does not vanish from equation (19) for the case when magma overflows form the conduit during slug ascent.
[25] Using this result, the stability index can be recast in terms of the dimensionless slug volume. For the standard model, $\gamma=A^{\prime} L_{a}^{\prime}$ (equation (13)); hence, from equation (19),

$$
\gamma=\frac{V_{a}^{\prime} A^{\prime}}{1-A^{\prime}}
$$

whereas for the overflow model, $\gamma=L_{a}^{\prime}$; hence,

$$
\gamma=\frac{V_{a}^{\prime}}{1-A^{\prime}}
$$

Equations (20) and (21) allow us to plot the burst overpressure as a function of dimensionless slug volume (Figure 4). Figure 4 demonstrates the key role that the dimensionless film cross section, $A^{\prime}$, plays in determining slug burst behavior; the controls on this parameter are discussed in detail in section 4. It also shows that the burst overpressures expected when magma overflows from the conduit during slug ascent (as in the case of the paroxysmal eruptions of 5 April 2003 and 15 March 2007) are higher than when magma is confined to the conduit during slug ascent. This increase in burst overpressure is more pronounced for thin falling films (small $A^{\prime}$ ) than for thick falling films.

[26] The equations presented here allow one to calculate various parameters of practical interest, including the slug overpressure at burst, slug length at burst, and the depth at which the slug becomes unstable. These quantities can be calculated for specific slug burst events if the parameters $\rho$, $g, P_{a}, r_{c}, V_{a}$, and $A^{\prime}$ can be calculated, measured, or estimated from field data. A dimensional worked example is presented in section 5 .

\section{Volcano-Scale Parameters}

[27] In this section we introduce a set of parameters and data distilled from previous works on Stromboli. We will use these in section 5 to derive ranges for various dimensionless parameters that are appropriate for volcano-scale conditions and to calculate burst overpressure at Stromboli. A summary of parameters presented in this section is given in Table 1.

\subsection{Magma Viscosity, Density, and Melt-Gas Surface Tension}

[28] The in situ viscosity of the magma filling the conduit system at Stromboli cannot be measured directly but may be estimated from laboratory rheometry of natural samples or using published rheological models; in which case, appropriate values for temperature, pressure, magmatic composition,

Table 1. Summary of Parameters and Their Ranges Used in Application of the Model to the Eruptions of Stromboli Volcano ${ }^{a}$

\begin{tabular}{lc}
\hline \multicolumn{1}{c}{ Parameter } & Range \\
\hline Gravitational acceleration $\left(\mathrm{m} / \mathrm{s}^{2}\right)$ & 9.81 \\
Atmospheric pressure $(\mathrm{Pa})$ & $10^{5}$ \\
Newtonian viscosity of magma (Pa s) & from 10 to $10^{4}$ \\
Density of magma $\left(\mathrm{kg} / \mathrm{m}^{3}\right)$ & 1300 and 2600 \\
Conduit radius $(\mathrm{m})$ & $(0$ and $50 \%$ vesicularity) \\
Slug volume $\left(\mathrm{m}^{3}\right)$ & 1.5 and 3 \\
\end{tabular}

\footnotetext{
${ }^{\mathrm{a}} \mathrm{See}$ section 4 for references and critical discussion.
} 
and crystal and bubble contents must be assumed. All of these quantities may vary dramatically with position in the conduit and between periods of normal and paroxysmal activity; hence, there is a very broad range of plausible values for the magma viscosity.

[29] For bubble-free primitive melts at depths $>3 \mathrm{~km}$, the empirically derived equation of Misiti et al. [2009] gives a viscosity of $\sim 5 \mathrm{~Pa}$ s for a Stromboli potassium-rich (HK) basalt with a $3.36 \mathrm{wt} \%$ added water content (representative of the more primitive basaltic melts, following Métrich et al. [2001] and Bertagnini et al. [2003], who found 2-3.4 wt \% $\mathrm{H}_{2} \mathrm{O}$ in trapped melt inclusions in olivine crystals basalts) at a temperature of $1150^{\circ} \mathrm{C}$. This is much lower than the pure melt viscosity of $\sim 350 \mathrm{~Pa} \mathrm{~s}$ at $1157^{\circ} \mathrm{C}$ reported by Vona et al. [2011] for Stromboli HK samples. This discrepancy is probably due to loss of water during the sample preparation procedure employed by Vona et al. [2011].

[30] The presence of crystals at subliquidus temperatures has a strong impact on the rheology of the magma, introducing shear thinning behavior and other non-Newtonian phenomena [Ishibashi, 2009; Mueller et al., 2010]. An important manifestation of this impact is a dramatic increase in magma viscosity with increasing crystal content; this is most pronounced for elongate crystals [Mueller et al., 2011], which are typical of Stromboli basalts (mean aspect ratio $\sim 7$ [Vona et al., 2011]). Vona et al. [2011] measured the viscosity of Stromboli HK basalts in the subliquidus temperature range $T=1187.5^{\circ} \mathrm{C}-1156.7^{\circ} \mathrm{C}$, corresponding to crystal volume fractions in the range $\sim 10 \%$ to $\sim 30 \%$; they found that the crystals increased the magma viscosity by a factor of $\sim 1.5$ ( $\sim 270 \mathrm{~Pa} \mathrm{~s})$ for the lowest crystal content, rising to a factor of $\sim 13$ ( $\sim 4400 \mathrm{~Pa} \mathrm{~s})$ for the highest crystal content.

[31] The presence of bubbles may also have a strong impact on magma rheology and viscosity [Stein and Spera, 2002; Llewellin et al., 2002]. The viscosity of bubbly magma at $3 \mathrm{~km}$ is computed as $100 \mathrm{~Pa}$ s by Allard [2010] on the basis of the viscosity of bubble-free melt derived from the equation of Hui and Zhang [2007]. Shallower than this depth, the magma starts crystallizing and mingles with a more viscous $\left(\sim 10^{4} \mathrm{~Pa} \mathrm{~s}\right)$, crystal-rich, partially degassed magma residing in the conduit and/or recycled from the uppermost portion of the plumbing system [Landi et al., 2004, and references therein]; hence, estimates of the viscosity of the magma filling the portion of the conduit system at Stromboli that is shallower than $3 \mathrm{~km}$ vary from around $10^{2}$ to $10^{4} \mathrm{~Pa} \mathrm{~s}$.

[32] The density of the magma varies according to its vesicularity. Various textural studies [Métrich et al., 2001; Bertagnini et al., 2003; Lautze and Houghton, 2005, 2007; Polacci et al., 2009] have shown the presence of both highdensity (low vesicularity) and low-density (40\%-50\% vesicularity) magmas in the uppermost part of the conduit. For a pure basaltic melt we use a typical density value of $2600 \mathrm{~kg} / \mathrm{m}^{3}$ [Murase and McBirney, 1973], which gives a density of $1300 \mathrm{~kg} / \mathrm{m}^{3}$ for the most vesicular magma.

[33] Murase and McBirney [1973] provide surface tension data for several silicate liquids in an argon atmosphere. Their data for basaltic liquids fall in the range $0.25-0.4 \mathrm{~N} / \mathrm{m}$. A value of $0.4 \mathrm{~N} / \mathrm{m}$ was previously applied by Seyfried and Freundt [2000] and James et al. [2008] for slugs in basaltic magma. We are not aware of any direct measurements of surface tension for Stromboli basalts, so we adopt this value.

\subsection{Conduit Geometry and Dimensions}

[34] In common with most other physical and numerical models of volcanic eruptions, we assume that the volcanic conduit is a vertical, cylindrical pipe. Since this geometry minimizes heat loss, a stable plumbing system might be expected to evolve toward cylindrical morphology over time; given the unusually long-lived stability of eruptive behavior at Stromboli [Rosi et al., 2000], this assumption is perhaps more valid here than at most other volcanoes. The diameter of the conduit has not been measured directly but may be inferred from visual estimates of the dimensions of the exploding slugs and the diameter of the vents at Stromboli, which are of the order of 2 to $5 \mathrm{~m}$ [Chouet et al., 1974; Vergniolle and Brandeis, 1996]. Burton et al. [2007b] have inferred the conduit radius $\left(r_{c}\right)$ as a function of pressure by applying mass conservation to magma flow rate, obtaining $r_{c} \sim 1.5 \mathrm{~m}$ at $200 \mathrm{MPa}$ and $1.3 \mathrm{~m}$ at $50 \mathrm{MPa}$. We follow James et al. [2008, 2009] and choose as a reference value $r_{c}=$ $1.5 \mathrm{~m}$ for all calculations in section 5 . We further explored the effect of $r_{c}=3 \mathrm{~m}$ when calculating overpressure as a function of volume (section 6).

\subsection{Slug Volumes}

[35] At Stromboli the typical volume of gas emitted during a single, short-lived explosion, characteristic of normal activity, has been estimated by several field methods. Harris and Ripepe [2007a] report volumes for gas "puffers" (nonpassive degassing phenomena, where the gas is erupted with an overpressure but is not associated with ejection of pyroclasts) of around of $50-190 \mathrm{~m}^{3}$ that correspond to gas masses around 10-30 kg. Vergniolle and Brandeis [1996] estimate the radius, length, and overpressure of slugs by matching synthetic acoustic pressure waveforms to recorded signals from 36 eruptions at Stromboli. They estimate slug volumes in the range $10-100 \mathrm{~m}^{3}$, with the volume depending strongly on the value chosen for the thickness of the liquid film above the slug at the point of burst. Following this approach, Ripepe and Marchetti [2002] find volumes of $20-35 \mathrm{~m}^{3}$ from infrasound measurements of a series of eruptions during September 1999. Photoballistic determination of gas emission reported by Chouet et al. [1974] yields typical volumes of $10^{3} \mathrm{~m}^{3}$. Volume estimates inferred by Chouet et al. [2003] from seismic measurements range from $7 \times 10^{3}$ to $2 \times 10^{4} \mathrm{~m}^{3}$. UV measurements of $\mathrm{SO}_{2}$ fluxes from a series of eruptions in October 2006 indicated volumes in the range $1.5-4 \times 10^{3} \mathrm{~m}^{3}$ [Burton et al., 2007a; Mori and Burton, 2009].

[36] Paroxysmal eruptions are associated with slugs of much larger volume; Ripepe and Harris [2008] inferred the ejection velocity of the gas-particle mixture erupted by the paroxysm on 5 April 2003 using multimodal data obtained from a thermal-seismic-infrasonic array. They then used the velocity data to estimate that a gas volume of $6 \times 10^{5} \mathrm{~m}^{3}$ was erupted during the paroxysmal eruption.

\subsection{Slug Ascent Velocity}

[37] In previous models of slug flow at Stromboli [Vergniolle and Brandeis, 1996; James et al., 2004, 2008; O'Brien and Bean, 2008; Allard, 2010; Pino et al., 2011], slug ascent velocity has been evaluated using the empirical correlation of Wallis [1969]. Viana et al. [2003] present a 
Table 2. Dimensionless Parameters for Scaling System Behavior

\begin{tabular}{cc}
\hline Dimensionless Groups & Volcano-Scale Conditions \\
\hline$F r=\frac{v_{s}}{\sqrt{2 g r_{c}}}$ & $0.02-0.34$ \\
$E o=\frac{4 \rho g r_{c}^{c}}{\sigma}$ & $2.9 \times 10^{5}$ to $2.3 \times 10^{6}$ \\
$M o=\frac{g \eta^{4}}{\rho \sigma^{3}}$ & $5.9 \times 10^{2}$ to $1.2 \times 10^{15}$ \\
$N_{f}=\frac{\rho}{\eta} \sqrt{8 g r_{c}{ }^{3}}$ & $2.1-1.2 \times 10^{4}$ \\
$\operatorname{Re}=N_{f} F r$ & $0.04-4 \times 10^{3}$ \\
\hline
\end{tabular}

thorough, and more up to date, review of available slug velocity data and use it to derive a well-validated empirical correlation (presented in section 4.5); this can be used to calculate ascent velocity from magma viscosity and density and conduit radius. Both correlations yield slug base ascent velocities $v_{s}$ (or likewise, in the absence of expansion, slug nose ascent velocities) in the range $0.11-2.6 \mathrm{~m} / \mathrm{s}$ for Stromboli parameters. These theoretical values differ significantly from the ascent velocities of 10-70 m/s inferred by Harris and Ripepe [2007b] from the delay between seismic and infrasonic signal arrival times. Their measurements reflect slug behavior only in the uppermost portion of the conduit ( $\sim 250 \mathrm{~m}$ below the crater terrace) and may be influenced by the rapid expansion of the slugs in that region [James et al., 2008]. Consequently, we follow Viana et al. [2003] when deriving slug ascent velocities.

\subsection{Thickness of the Falling Film}

[38] The analysis in section 3 demonstrates the crucial role of the thickness of the falling film (expressed as the dimensionless film cross section, $A^{\prime}$ ) in our model. It is important, therefore, to quantify what values the film thickness may take in a volcanic system. Several previous theoretical and experimental studies have investigated the physical controls on the thickness of the falling film $(\lambda=$ $r_{c}-r_{s}$ ) around a rising gas slug. New experiments and theory [Llewellin et al., 2011] show that when surface tension effects are unimportant, all of the published expressions for dimensionless film thickness $\left(\lambda / r_{c}\right)$ can be recast as functions of the "inverse viscosity" [Wallis, 1969],

$$
N_{f}=\frac{\rho}{\eta} \sqrt{8 g r_{c}^{3}} .
$$

The inverse viscosity is obtained by combining the Morton number $M o$ (which represents the ratio of viscous and surface tension forces)

$$
M o=\frac{g \eta^{4}}{\rho \sigma^{3}}
$$

and the Eötvös number Eo (which represents the ratio of buoyancy and surface tension forces)

$$
E o=\frac{4 \rho g r_{c}^{2}}{\sigma}
$$

in order to eliminate surface tension.

[39] The dimensionless film thickness $\lambda^{\prime}=\lambda / r_{c}$ is related to $A^{\prime}$ by

$$
A^{\prime}=\lambda^{\prime}\left(2-\lambda^{\prime}\right)\left(\text { hence also } \lambda^{\prime}=1-\sqrt{1-A^{\prime}}\right) .
$$

Surface tension plays a negligible role in determining slug behavior when Mo $>10^{-6}$ [Seyfried and Freundt, 2000] and Eo $>40$ [Viana et al., 2003] (using parameter values from Table 1 and the surface tension value given in section 4.1, we find that for Stromboli, $10^{2}<M o<10^{14}$ and $10^{5}<E O<$ $10^{6}$ ). The inverse viscosity is also related to the slug Reynolds number $(R e)$, which is sometimes used to characterize volcanic slugs [Vergniolle and Brandeis, 1996; Harris and Ripepe, 2007b] via

$$
R e=\frac{2 \rho v_{s} r_{c}}{\eta}=F r N_{f},
$$

where $v_{s}$ is the ascent velocity of the slug and $F r$ is the Froude number, which is a dimensionless measure of slug ascent velocity in the absence of expansion:

$$
F r=\frac{v_{s}}{\sqrt{2 g r_{c}}} .
$$

An empirical expression relating inverse viscosity and Froude number is given in Appendix A (equation (A4), derived from Viana et al. [2003]).

[40] Table 2 reports dimensionless parameters for volcanic slugs calculated assuming typical Stromboli parameters given in Table 1. Their values are such that surface tension plays a negligible role for volcanic slugs; hence, their morphology and ascent velocity are predominantly controlled by inertial and viscous forces.

[41] New experimental data for film thickness $\lambda^{\prime}\left(N_{f}\right)$ are now available [Llewellin et al., 2011] over the range $0.1<N_{f}<10^{5}$ and in the regime where surface tension can be neglected. This inverse viscosity range encompasses the range that is appropriate for Stromboli $\left(10<N_{f}<10^{4}\right.$ from the parameters in Table 1). We recast these data as $A^{\prime}\left(N_{f}\right)$ using equation (25) to examine the validity of models for film thickness (discussed in detail in Appendix A) previously applied to volcanic systems: the Brown [1965] model (equation (A1)), applied by Seyfried and Freundt [2000] and James et al. [2008], and the simple Batchelor [1967] model (equation (A5)), applied by James et al. [2008, 2009] and Vergniolle et al. [2004]. We also test more recent works on film thickness: the combined Batchelor [1967] and Viana et al. [2003] expression (equations (A3) and (A4)), the Nogueira et al. [2006] experiments, and the Kang et al. [2010] model (equation (A6)). The comparison is plotted in Figure 5.

[42] The data in Figure 5a describe a clear sigmoidal shape, with well-defined asymptotic regions at low and high $N_{f}$, where film thickness is independent of inverse viscosity. In the low- $N_{f}$ asymptotic region $\left(N_{f}<10\right)$, the film occupies around $55 \%$ of the conduit cross section $\left(A^{\prime}=0.55\right)$; in the high- $N_{f}$ asymptotic region $\left(N_{f}>10^{4}\right)$, the film occupies only $15 \%$ of the conduit cross section $\left(A^{\prime}=0.15\right)$. In the region between these two asymptotes $\left(2<N_{f}<10^{4}\right)$, the film thickness shows a logarithmic dependence on inverse viscosity; it is notable that this region (shaded in Figure 5) coincides with the range of inverse viscosity expected for Stromboli, indicating that $A^{\prime}$ may assume any value in the range $0.15<A^{\prime}<0.55$, depending on the physical properties of the magma and the dimensions of the conduit. New experiments and theory [Llewellin et al., 2011] show that the falling film around the slug undergoes a transition to 

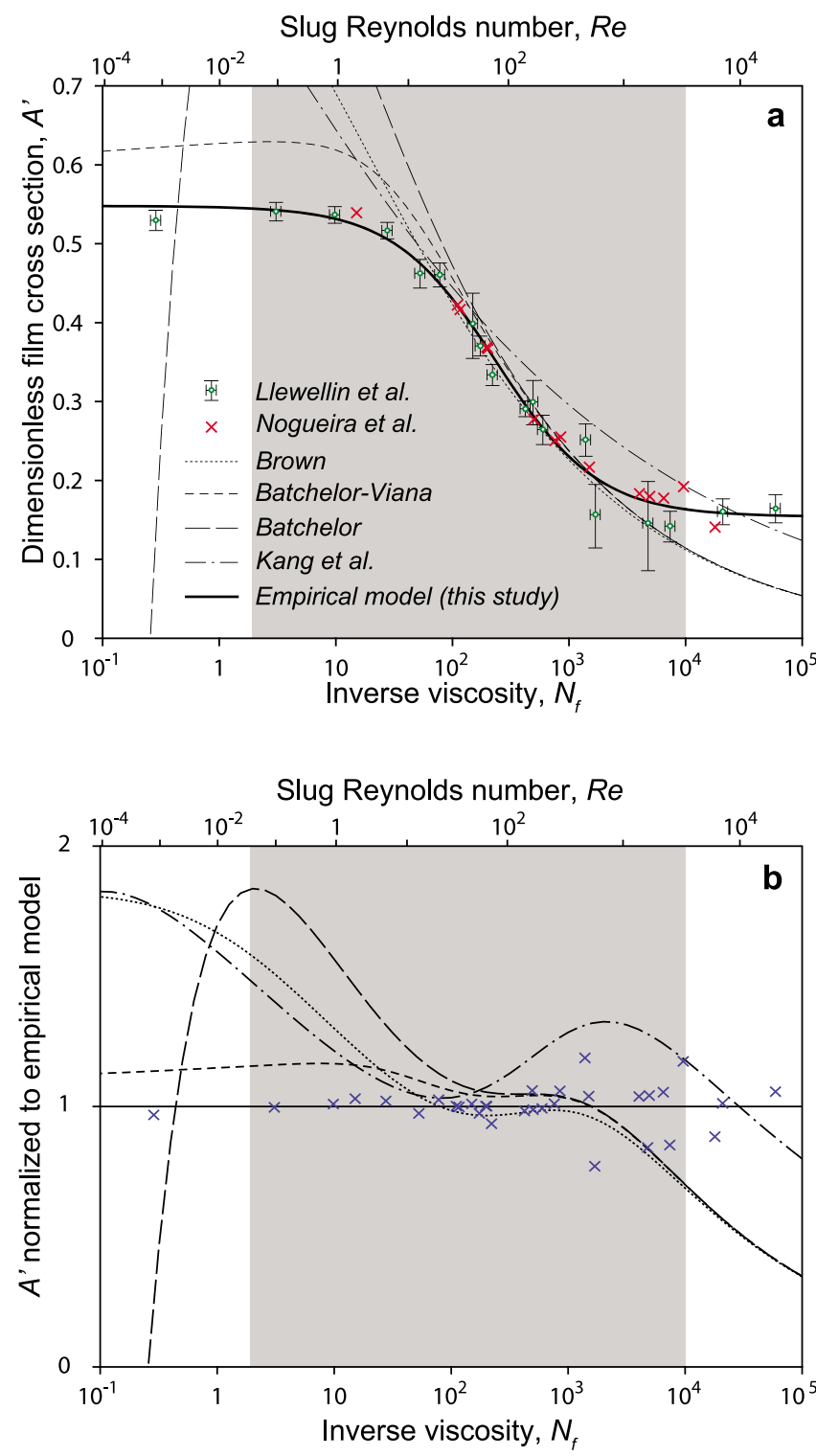

Figure 5. Comparison of models for dimensionless film cross section $A^{\prime}$ as a function of dimensionless inverse vis$\operatorname{cosity} N_{f}$ (or related Reynolds number $R e$ ) with experimental data from Llewellin et al. [2011] and Nogueira et al. [2006]. The shaded areas show the range of values of $N_{f}$ that is relevant to gas slugs at Stromboli (from parameters in Table 1). (a) Lines show the predictions of various models for $A^{\prime}\left(N_{f}\right)$ (section 4.5). The published models show good agreement with the data at intermediate values of $N_{f}$ but perform poorly at the extremes. We propose a new empirical expression (solid line, equation (28)) which is valid across the volcanologically relevant range of $N_{f}$, and beyond. (b) The data and models presented in Figure 5a are shown normalized to the new empirical model to give a clearer demonstration of the quality of fit provided by each model across the range of $N_{f}$.

turbulence at $N_{f}>3000$, indicating that turbulent falling films are possible at Stromboli.

[43] Of the previously applied models, Brown's [1965] model and the combined Batchelor [1967] and Viana et al.
[2003] model perform fairly well in the volcanically relevant range of $N_{f}$; however, they both overpredict film thickness at the low end of the range and underpredict at the high end (although we note that the data scatter is greatest in the range $10^{3}<N_{f}<10^{4}$ ). The simple Batchelor model performs poorly for $N_{f}<100$. The Kang et al. [2010] model generally performs poorly, except over a very limited range of $N_{f}$. Following the most recent work [Llewellin et al., 2011], we derive a new empirical expression for $A^{\prime}\left(N_{f}\right)$ :

$$
A^{\prime}=0.351+0.197 \tanh \left(2.71-1.14 \log _{10} N_{f}\right),
$$

choosing the same functional form as their expression for $\lambda^{\prime}\left(N_{f}\right)$. Equation (28) provides an excellent fit to data across the full range of inverse viscosity $\left(0.1<N_{f}<10^{5}\right)$, and we use it to calculate the $A^{\prime}$ values for our overpressure model in section 5. In Figure 5b, all of the models presented in Figure $5 \mathrm{a}$ are normalized to equation (28), allowing the quality of fit provided by each model to be directly compared.

\section{Model Results for the Stromboli Case}

[44] The nondimensional approach developed in section 3 allows the model to be applied to any system involving bursting of slugs of gas. Geological examples include, for example, geysers, hydrothermal eruptions, mud volcanoes, and multiphase borehole flows, as well as basaltic volcanoes. In this section we apply the model to the specific case of Stromboli volcano. Stromboli provides the ideal test case because its eruptions have been so well characterized (sections 2 and 4). The model we present allows several parameters of volcanological interest to be calculated. Given the parameters in Table 1, the maximum size for a stable slug can be calculated. Then, if the size of a slug can be measured, estimated, or (for hypothetical cases) assumed, the model can be used to determine (1) the gas pressure within the slug at busting, (2) the slug length at bursting, and (3) the depth at which the slug becomes unstable. In Appendix B, we illustrate the practical application of the system of equations through a worked example. We also give instructions for the use of the electronic spreadsheet file provided in the auxiliary material (Table S1).

[45] In this section, we use the model to explore the role played by the various physical properties of the slug-conduit system in controlling eruption parameters for the case of Stromboli volcano. We explore the input parameter space defined by the values in Table 1, keeping conduit radius fixed at $1.5 \mathrm{~m}$.

[46] Magma viscosity exerts a strong control on slug behavior through its influence on the thickness of the falling film of magma around the gas slug (section 4.5). Figure 6 illustrates the relationship between magma viscosity and the maximum stable slug size (i.e., the amount of gas that a slug can contain, expressed as the volume the slug would have at atmospheric pressure, above which the slug will burst with an overpressure). Figure 6 shows that when viscosity is low (thin film), a slug must contain more gas in order to burst with an overpressure than when viscosity is

\footnotetext{
${ }^{1}$ Auxiliary materials are available in the HTML. doi:10.1029/ 2011JB008747.
} 


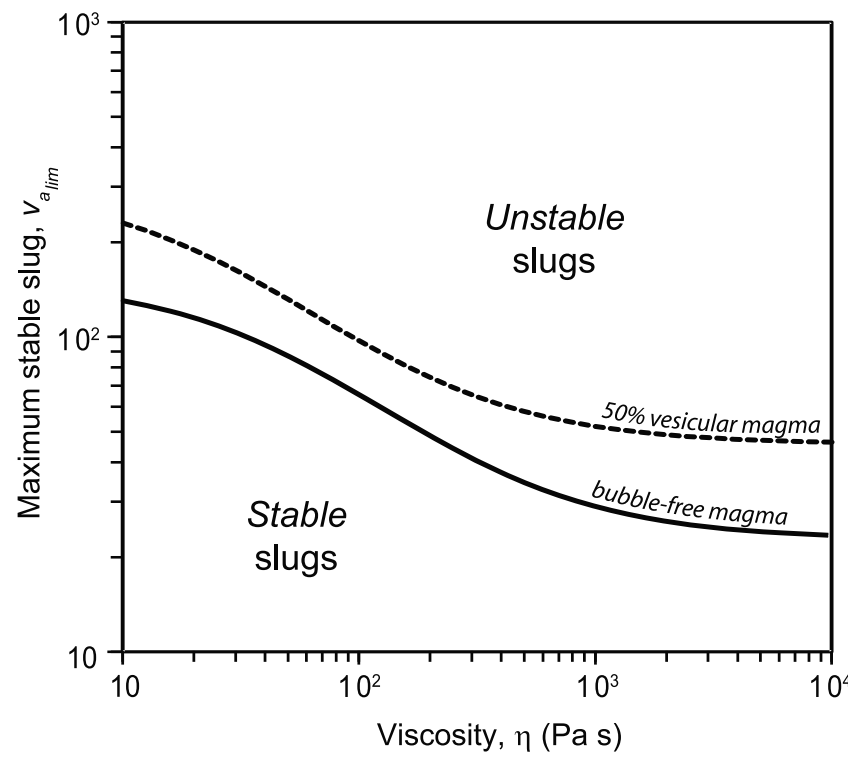

Figure 6. Maximum size of a slug (expressed as its equivalent volume at atmospheric pressure $V_{\text {a lim }}$ ) that can rise to the surface in equilibrium with magma-static pressure, as a function of magma viscosity $\eta$, for plausible conditions at Stromboli volcano (Table 1). Solid and dashed lines represent bubble-free magma and 50\% vesicular magma, respectively. The curves mark the transition between slugs that reach the surface in pressure equilibrium (stable slugs) and slugs that reach the surface with an overpressure (unstable slugs).

high (thick film). For Stromboli, when the magma is bubble free and has viscosity $10^{4} \mathrm{~Pa} \mathrm{~s}$, the standard model predicts that a slug will burst with an overpressure when it contains at least an amount of gas equivalent to a volume of $24 \mathrm{~m}^{3}$ at atmospheric pressure; if the magma viscosity is only $10 \mathrm{~Pa} \mathrm{~s}$, then the threshold volume is $130 \mathrm{~m}^{3}$. Magma density also plays an important role, illustrated in Figure 6; the equivalent thresholds for magma with $50 \%$ vesicularity are $46 \mathrm{~m}^{3}$ and $229 \mathrm{~m}^{3}$, respectively.

[47] Figure 7 summarizes the three main model outputs (slug pressure and length at bursting and depth at which the slug becomes unstable) over the broad range of Stromboli conditions described in section 4 for both the standard and overflow models. The amount of gas in the slug, expressed as the equivalent slug volume at atmospheric pressure $\left(V_{a}\right)$, has the strongest control, shifting by orders of magnitude all calculated output parameters as it ranges from $10^{2}$ to $10^{6} \mathrm{~m}^{3}$. Bursting pressure $\left(P_{b}\right)$ (Figure 7a) ranges from 1 to $10^{2}$ bars over this slug volume range and increases nonlinearly with increasing viscosity. Notably, although the model considers only geometrical and magma-static factors, significant overpressures are predicted to develop.

[48] Slug length at bursting $\left(L_{b}\right)$ (Figure 7b) ranges from 10 to $5 \times 10^{3} \mathrm{~m}$ over the same range of slug volumes but decreases as viscosity increases. This very large range of slug lengths has important implications for model applicability, which are discussed in section 6.2. The depth at which the slug becomes unstable $\left(h_{\text {lim }}\right)$ (Figure $7 \mathrm{c}$ ) ranges from 0 to $10^{3} \mathrm{~m}$ below the magma-free surface and depends more strongly on magma viscosity for smaller slug size.

[49] At Stromboli, variations in magma density play a more minor role in controlling output parameters than variations in magma viscosity and slug volume, mainly because of the relatively small range of plausible densities. Halving the magma density (i.e., assuming $50 \%$ vesicularity) leads to lower slug pressure and longer slug length at burst. For most conditions of interest, lower density also corresponds to greater depth of instability, although we note the inverse for the overflow model when slugs are small and viscosity is
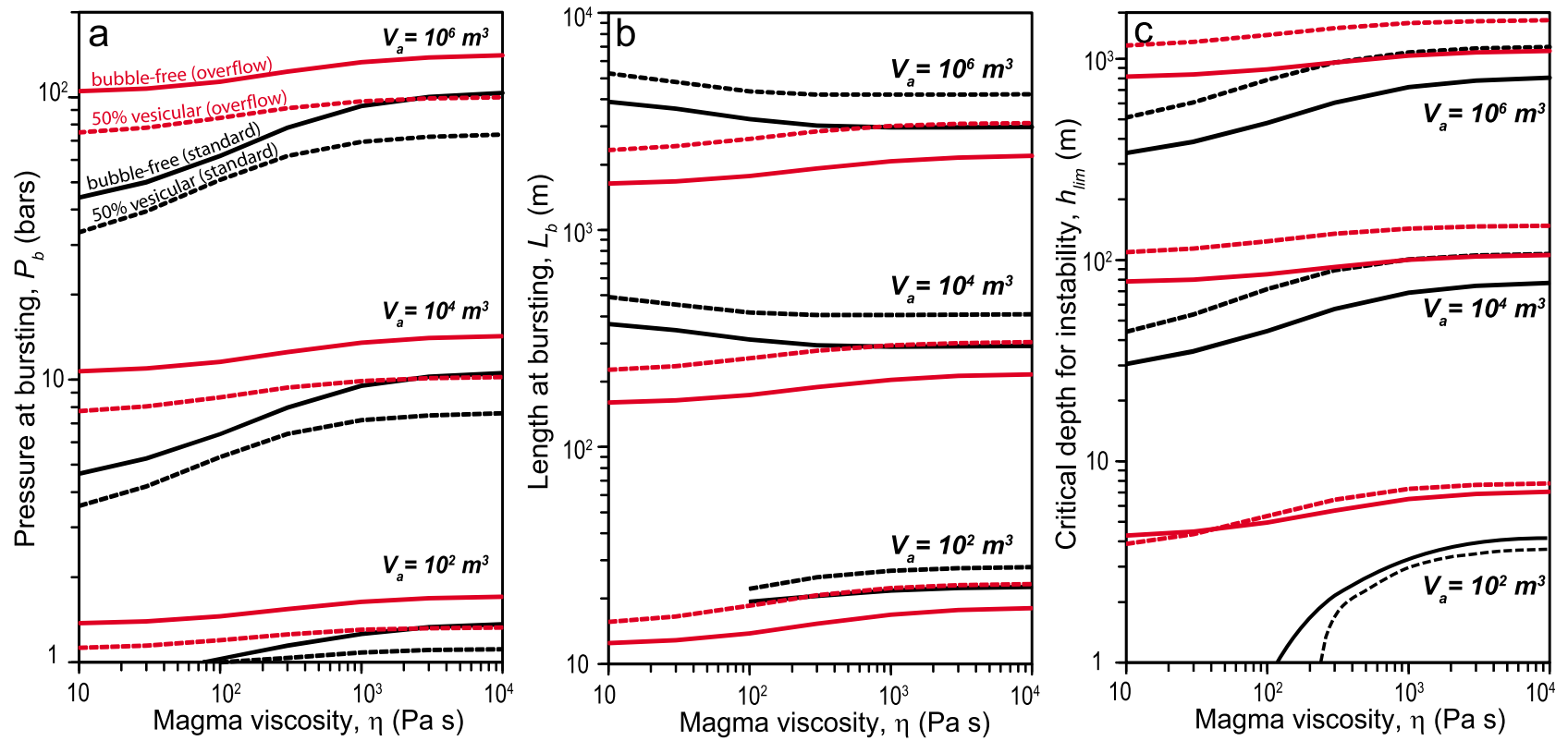

Figure 7. Effect of viscosity $(\eta)$ and slug gas volume $\left(V_{a}\right)$ on (a) pressure at bursting $\left(P_{b}\right)$, (b) length at bursting $\left(L_{b}\right)$, and (c) depth of slug instability $\left(h_{\text {lim }}\right)$ at Stromboli. Solid and dashed lines represent bubblefree magma and 50\% vesicular magma, respectively. Black and red curves represent the standard and the overflow model, respectively. Parameter values are taken from Table 1. 

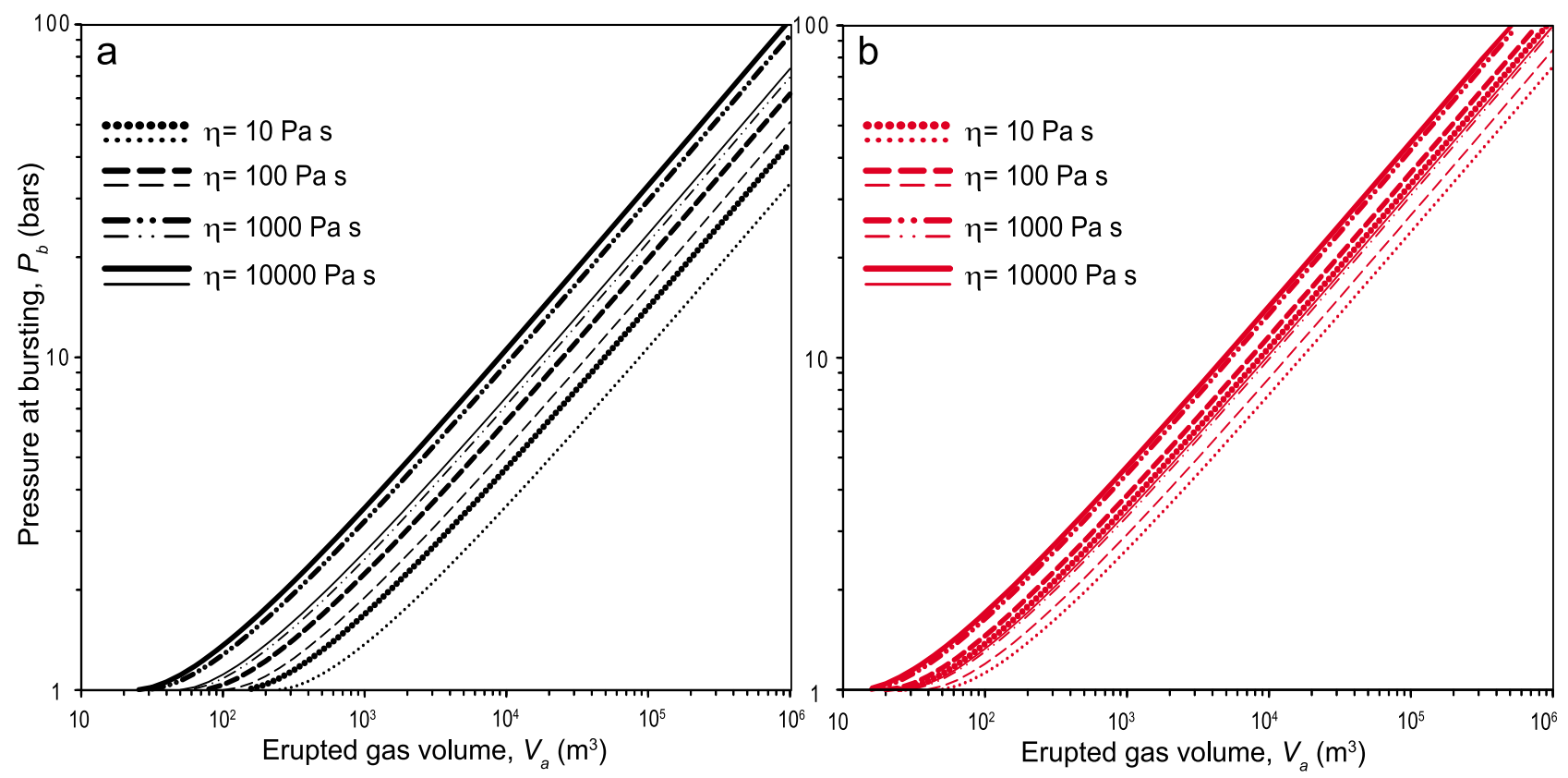

Figure 8. Bursting pressure of an erupting gas slug $\left(P_{b}\right)$ at Stromboli as a function of slug size (expressed as equivalent volume at atmospheric pressure, $V_{a}$ ), for (a) the standard and (b) the overflow model. Different curves represent model output calculated for the range of $A^{\prime}$ values corresponding to magma viscosities of $10-10^{4} \mathrm{~Pa} \mathrm{~s}$. Thick and thin lines represent bubble-free magma and $50 \%$ vesicular magma, respectively.

low (Figure 7c). In general, the overflow model predicts higher slug pressure and shorter slug length at bursting than the standard model. Furthermore, the influence of viscosity on results is greatly reduced for the overflow model compared with the standard model.

[50] We anticipate that the relationship of greatest practical interest, i.e., more directly linked to field measurable quantities, is that between slug volume and bursting pressure. We present this relationship in Figure 8, echoing the dimensionless results presented in Figure 4. The results for both the standard (Figure 8a) and the overflow (Figure 8b) models illustrate the strong dependence of $P_{b}$ on $V_{a}$. For slug volumes $V_{a}>10^{3}$, we find the approximate relationship $P_{b} \propto \sqrt{V_{a}}$. Comparing Figures $8 \mathrm{a}$ and $8 \mathrm{~b}$ we observe, again, the reduced influence of viscosity, and enhanced bursting pressure for the overflow case.

\section{Discussion}

\subsection{Model Assumptions and Limitations}

[51] A key outcome of our analysis is that the gas volume and explosion pressure of a slug (key quantities that can be related to field-based measurements) are linked in a straightforward way through the parameter $A^{\prime}$, which is related to magma viscosity and conduit geometry. Our simplified model provides a first-order approximation of the gas overpressure that develops during Strombolian eruptions. This value for the slug pressure at burst can be considered a minimum bound for four reasons. First, we assume that the slug base is stationary during the burst process; in reality, it will continue to rise, shortening the slug and increasing the pressure of the gas within it. Second, we assume that the thickness of the film of magma that falls around the slug remains constant throughout the burst process. Evidence from laboratory analogue experiments indicates that the slug nose actually becomes more pointed as it accelerates toward the surface during bursting, leading to a thicker falling film [James et al., 2008, Figure 2; Corder, 2008, pp. 182-185]. Consequently, the slug is shorter when it bursts than is predicted under the assumption of constant film thickness, implying a higher burst pressure. Third, we neglect inertia and viscosity in the accelerating body of magma above the expanding slug which, in reality, will act to retard slug growth, hence increasing overpressure. Finally, the fact that Strombolian eruptions eject magma (albeit a modest volume) implies that the slug bursts while the head region of magma above the slug still has finite thickness. Consequently, the overpressure within the slug is higher than predicted by our model, which assumes that bursting occurs when $h \rightarrow 0$.

[52] James et al. [2008] developed a 1-D model that includes viscosity and inertia in the magma above the expanding slug, in addition to magma-static effects. When compared with the results of their model (which uses a magma viscosity of $500 \mathrm{~Pa} \mathrm{~s}$; a range of conduit radius of 2 , 1.5 , and $1 \mathrm{~m}$; a slug base ascent velocity $1.71 \mathrm{~m} / \mathrm{s}$ ), our simplified model underestimates overpressure by about $35 \%$ in the worst case.

[53] The assumption of a cylindrical conduit of constant diameter is clearly an oversimplification. Very long period seismic signals from Strombolian explosions at Stromboli are best fit by a source model incorporating a transition from a cylindrical shallow conduit to an inclined dike-like structure at a depth $\sim 200-300 \mathrm{~m}$ below the craters [Chouet et al., 2003]. While our simple model does not account for such complex geometries, the effect of a shallow widening of the 


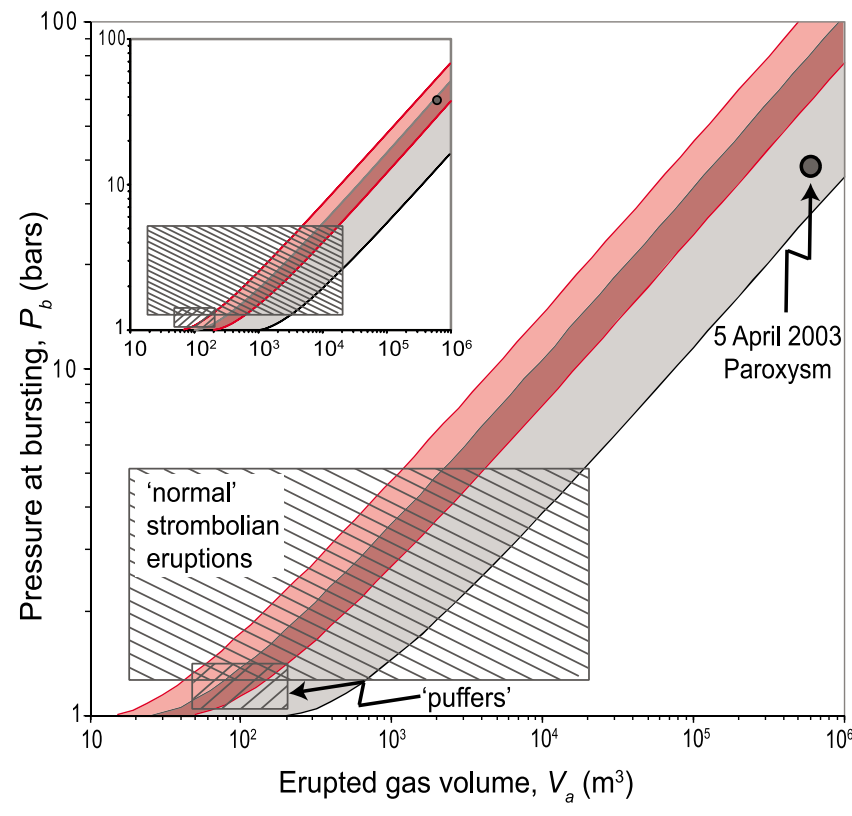

Figure 9. Application of overpressure model to explosive activity at Stromboli. The gray and red shaded areas represent bursting pressure $P_{b}$ as a function of slug gas volume $\left(V_{a}\right)$ in the standard and overflow cases, respectively, per Figure 8. Literature estimates for burst pressures and volumes for a range of eruption styles at Stromboli are shown (puffers [Ripepe et al., 2002; Harris and Ripepe, 2007a], normal Strombolian eruptions [Vergniolle and Brandeis, 1996; Ripepe and Marchetti, 2002], and 5 April 2003 paroxysmal eruption [Ripepe and Harris, 2008]). The inset illustrates model results for a conduit radius $\left(r_{c}\right)$ of $3 \mathrm{~m}$.

conduit can be assessed qualitatively by assuming a wider conduit than the $1.5 \mathrm{~m}$ radius used in section 5 and Figures 6, 7, and 8 (Figure 9). A further complexity in the natural system is that direct observation shows that three vent groups are persistently active at Stromboli with different outlet diameters, which are fed by shallow conduits connected at some depth [e.g., Rosi et al., 2000, and references therein]. The observed variations in intensity and duration of Strombolian explosions from the different vents [e.g., Chouet et al., 1974; Ripepe and Marchetti, 2002; Patrick et al., 2007] may be linked, according to our model, to different conduit diameters above the branching depth. For instance, during 2009 the central vent group produced mainly puffing and showed a larger diameter at the surface, which would agree well with model predictions that, other factors being equal, a wider conduit results in reduced overpressure (Figure 9).

[54] Besides conduit geometry, our model does not take into account spatial heterogeneities in magma properties present within the Stromboli conduit. It has been proposed that the magma in Stromboli's plumbing system is vertically zoned, with a relatively evolved, crystal-rich and gas-poor magma occupying the upper few kilometers of the conduit, overlying, and mixing variably with, a crystal-poor and gasrich magma [e.g., Landi et al., 2004; Métrich et al., 2010]. At a very shallow level, the crystal-rich end-member shows horizontal variations in density and rheology caused by the presence of a less vesicular magma at the conduit margins [e.g., Lautze and Houghton, 2005], and there are slight, but significant, chemical differences from one crater to the other [e.g., Landi et al., 2011].

[55] The vertical heterogeneity is likely only to impact on paroxysmal eruptions since our model results are insensitive of the slug ascent history below $h_{\text {lim }}$, which is on the order of hundreds of meters below magma surface for Strombolian explosions and only reaches kilometers in depth for paroxysmal explosions. Conversely, the horizontal heterogeneities may have strong implications for slug geometry and consequent overpressure at burst. For instance, Lautze and Houghton [2005] report textural evidences suggesting horizontal magma zoning within the conduit, with a more viscous, degassed magma lining conduit margins. As shown in Figure 6 , variation in viscosity can determine the transition from a stable to an unstable slug because of its influence on the parameter $A^{\prime}$. Lateral variations in magma viscosity could be incorporated into our model by choosing an appropriate value for $A^{\prime}$ to account for the rheological transition between the two magmas.

[56] Finally, our analysis should also apply if the gas phase rises in the conduit as a bubble raft rather than a slug. Experimental observation suggests similar behavior between bubble clusters and slugs in a liquid-filled cylindrical conduit [e.g., Corder, 2008]: the variation in film thickness along individual bubbles is negligible compared to the conduit radius, and the assumption of constant liquid film around the slug should still hold. Moreover, expansion during final ascent causes rapid coalescence of bubbles in the cluster, resulting in the burst of one or few large slugs. This is also in agreement with field evidences of multiple bubbles bursting during a single eruption at Stromboli [Taddeucci et al., 2012].

\subsection{Implications for Explosive Activity at Stromboli Volcano}

[57] In Figure 9 we compare our model results with existing estimates of eruptive gas budget and burst overpressure determined from field measurements of puffers [Ripepe et al., 2002; Harris and Ripepe, 2007a], normal Strombolian eruptions [Vergniolle and Brandeis, 1996; Ripepe and Marchetti, 2002], and for the 5 April 2003 paroxysmal eruption at Stromboli [Ripepe and Harris, 2008]. In general, the trend in burst overpressure with erupted gas volume agrees well with field-based estimates. In particular, the fact that all three types of eruption follow the predicted trend indicates that our approach, based on magma-static and geometrical considerations alone, is sufficient to account for observed eruptive overpressures across the spectrum of eruptive activity at Stromboli, from low-energy puffing through normal Strombolian eruptions up to paroxysmal explosions.

[58] Very good agreement between the model and data is obtained for puffer activity. If we use the $50-190 \mathrm{~m}^{3}$ range for the volume of released gas, estimated by Harris and Ripepe [2007a], as input to the model, we calculate pressure at bursting of 1.11-1.73 bars and 1.33-2.23 bars for the standard and overflow models, respectively. These values are in good agreement with the 1.1-1.4 bars range obtained from the oscillating gas bubble model of Vergniolle and Brandeis [1996]. Our model predicts that the slugs that cause puffing are a few meters to tens of meters long when 
they burst and that they become unstable (i.e., the burst process begins) when the slug nose is a few meters below the magma surface (Figure 7).

[59] While there is considerable overlap between the model and field data for normal Strombolian eruptions, the range of burst overpressures estimated from field observations (1.3-5 bars [Vergniolle and Brandeis, 1996; Ripepe and Marchetti, 2002]) is rather smaller than we predict (120 bars) if we take volume estimates of $20 \mathrm{~m}^{3}$ to $2 \times 10^{4} \mathrm{~m}^{3}$ as input for the model. This discrepancy probably reflects uncertainties both in field estimates and in our model assumptions. (For example, the upper value of 20 bars that we predict is based upon the assumption of a slug of volume $2 \times 10^{4} \mathrm{~m}^{3}$ bursting through highly viscous magma $\left(10^{4} \mathrm{~Pa}\right.$ s) during overflow; if, instead, we assume that the same slug bursts through low-viscosity (10 $\mathrm{Pa} \mathrm{s})$, low-density $\left(1300 \mathrm{~kg} / \mathrm{m}^{3}\right)$ magma which is confined to the conduit, as is likely for normal Strombolian activity, we find a burst pressure of 4.9 bars, which is in much closer agreement with field observations.) Our model predicts that bursting starts no deeper than $150 \mathrm{~m}$ below the magma surface and that the length of the slugs at burst is between a few meters and a few hundred meters (Figure 7). Vergniolle and Brandeis [1996] report rather shorter slug lengths of $0.7-33 \mathrm{~m}$, based on a model fit to their acoustic measurements; however, we note that these values are for slugs with volumes of the order of $100 \mathrm{~m}^{3}$, comparable with volumes reported for puffers [Harris and Ripepe, 2007a]. By contrast, Chouet et al. [1974] report that the length of the resonator during Strombolian explosions, which could include the length of the slug plus the overlying conduit, is in the range $280-400 \mathrm{~m}$. New observations and modeling based on high-speed videography and shock tube experiments suggest slug length at Stromboli of the order of 100-200 m [Taddeucci et al., 2012].

[60] Puffing and Strombolian activity are usually distinguished on the basis of bursting pressure. Colò et al. [2010] relate the amplitude of infrasonic signals to bursting overpressure and indicate that, for puffers, infrasonic amplitude is $<5 \mathrm{~Pa}$, while for "explosive" events it is $>5 \mathrm{~Pa}$. James et al. [2009] used the variation of measured signals in experimental modeling of slug burst to place the limit between passive degassing and bursting at $1>P_{s \text { lim }}^{\prime}>3$. Our model demonstrates that while slug volume exerts the strongest control on burst overpressure, magma properties and conduit geometry also have a role to play, mainly through their influence on the parameter $A^{\prime}$. Figure 9 shows that the volume of gas erupted during puffing events falls within the range for normal Strombolian activity, suggesting that variations in gas volume are not primarily responsible for determining whether puffing or Strombolian eruption occurs but rather that the distinction is a result of different magma properties or conduit radius. For instance, for $V_{a}$ equal to $100 \mathrm{~m}^{3}$ and a bubble-free magma, only slugs ascending in a magma with a viscosity higher than $1000 \mathrm{~Pa} \mathrm{~s}$ are predicted to erupt "explosively" whereas only puffing is expected, regardless of viscosity, for magma with $50 \%$ vesicularity (Figure 7). This implies that modest variations in magma vesicularity or crystallinity, as have been reported for Stromboli by, e.g., Lautze and Houghton [2007], could dictate whether puffing or Strombolian eruption occurs.
[61] Concerning paroxysmal explosions, the only relevant field data were collected for 5 April 2003 by Ripepe and Harris [2008], who used thermal and seismic data to infer a volume of gas of $5.7 \times 10^{5} \mathrm{~m}^{3}$ released during the main "peak" event, at a pressure of 38 bars. Using their volume estimate as input, the standard and overflow models predict a bursting pressure in the range 25-78 and 57-106 bars, respectively (Figure 9). We reject the standard model for this because it predicts that the length of the slug at burst is in the range $2-4 \mathrm{~km}$, which is inconsistent with the assumption that the magma above the slug is confined to the conduit. This supports the assertion of Calvari et al. [2011] that paroxysmal eruptions are associated with magma effusion.

[62] While the great slug length at burst may appear surprising, it is consistent with the observations that (1) paroxysmal explosions typically erupt a more primitive and gas-rich magma of deeper origin [Bertagnini et al., 2003; Métrich et al., 2010]; (2) the slugs which drive paroxysmal eruptions may have their origins as deep as $4 \mathrm{~km}$ below the vents, as suggested by geochemical composition of gas plume during both 5 April 2003 [Allard, 2010] and 15 March 2007 [Aiuppa et al., 2010]; and (3) the relatively long duration (6 min for the 5 April 2003 event [Ripepe and Harris, 2008]) of the observed paroxysmal eruptions.

[63] The overflow model prediction of the slug burst pressure is greater than the field estimate for 5 April 2003 by roughly a factor of 2 . The agreement is improved if we use a conduit radius of $3 \mathrm{~m}$, rather than the usual estimate of $1.5 \mathrm{~m}$ (inset in Figure 9); however, this change gives a worse agreement between field estimates and model results for puffers and normal Strombolian eruptions. This may be reconciled if we hypothesize that the conduit is wider at depth than in the shallow subsurface, since this would reduce the predicted overpressure for paroxysms, where the onset of slug burst may be as deep as $1.2 \mathrm{~km}$, but not for small slugs associated with puffing and normal Strombolian activity, which begin to burst at much shallower depths. Slug burst is predicted to begin when the slug nose is 600 $1200 \mathrm{~m}$ below the surface (Figure 7), which is rather deeper than the 80-150 m reported by Ripepe and Harris [2008] for the magma fragmentation level.

[64] Overall, we propose that our simple model of slugdriven eruption, in which only magma-static force balance and slug geometry are considered, can account for the wide range of gas bursting pressures occurring in a real volcanic scenario. This range at Stromboli encompasses puffing, Strombolian activity, and paroxysmal explosions. The good agreement between field-based estimates and our model results (Figure 9) strongly suggests that the bursting of overpressured slugs can be envisaged as a general mechanism to explain the entire spectrum of eruptive dynamics at Stromboli (as previously proposed by Allard [2010]).

\section{Conclusions}

[65] We develop a simple, analytical model for the rise and burst of gas slugs in a volcanic conduit. We use this model explore the physical controls on slug burst overpressure and hence explosion intensity; we find that the overpressure is determined by the amount of gas in the slug and by the thickness of the film of magma falling around the slug. The model neglects inertia and viscosity at the conduit 
scale and shows that significant overpressures can develop from geometric and magma-static considerations alone. Nondimensionalization of the model facilitates its application to any system in which gas slugs rise up a conduit or pipe (e.g., Strombolian and hydrothermal eruptions on Earth and other planets, geysers, mud volcanoes, and engineering applications).

[66] We express the thickness of the falling magma film through the dimensionless parameter $A^{\prime}$, which represents the fraction of the conduit's cross-sectional area that is occupied by the film. We present a new empirical model, based on carefully scaled laboratory experiments of slug ascent, which allows the value of the parameter $A^{\prime}$ to be computed if the density and viscosity of the magma, and the size of the conduit are known.

[67] When applied to volcanic scenarios, the model predicts that explosion overpressure in slug-driven basaltic eruptions should vary dramatically in response to variations in slug size, magma viscosity and density, and conduit diameter. As a case study, we model eruptions at Stromboli volcano, Italy, and find that the overpressure predicted by our model is in good agreement with previous field estimates for eruptions at Stromboli over its entire spectrum of explosive activity, from low-energy puffing, through normal Strombolian eruptions, up to paroxysmal explosions. This wide-ranging agreement suggests that it is plausible to envisage a common, slug-driven mechanism for all eruptive styles at Stromboli, providing further support to a slugrelated origin of paroxysmal eruption.

[68] Various geometrical and physical parameters for volcanic slugs can be calculated using our model, including slug size and radius, the thickness of the surrounding magma layer, depth of burst onset, and the evolution of pressure within the slug during ascent. Table $\mathrm{S} 1$ is provided in the auxiliary material to facilitate these calculations. Model outputs can be used as input parameters for more sophisticated eruption models and can be combined with geophysical monitoring information to better assess eruptive dynamics and associated hazards at basaltic volcanoes worldwide.

\section{Appendix A}

[69] In this appendix we report expressions for the thickness of the falling film $\left(\lambda=r_{c}-r_{s}\right)$ which have been derived from previous studies that have investigated the physical controls on film thickness around a rising gas slug. These models have been tested against experimental data [Llewellin et al., 2011]. Note that since the parameter of interest in the present study is the dimensionless film cross section $A^{\prime}$ (equation (6)), rather than the dimensionless film thickness $\lambda^{\prime}=\lambda$, we recast each of the models for film thickness, as $A^{\prime}\left(N_{f}\right)$ using equation (25).

[70] Seyfried and Freundt [2000] consider a gas slug rising in a conduit filled with basaltic magma and predict the thickness of the falling film of magma as a function of magma viscosity using an expression derived by Brown [1965]. New work [Llewellin et al., 2011] shows that this theoretical expression can be written in terms of the dimensionless quantities $\lambda^{\prime}$ and $N_{f}$ :

$$
\lambda^{\prime}=2 \frac{\sqrt{1+N}-1}{N}
$$

where $N=\sqrt[3]{14.5 N_{f}^{2}}$. The derivation of this relationship depends on the assumption of potential flow around the nose of the slug, which breaks down for $N_{f}<120$ [Llewellin et al., 2011].

[71] James et al. [2008] compare the Brown [1965] model with an alternative expression for film thickness derived by Batchelor [1967] in their investigation of the behavior of gas slugs at low-viscosity basaltic volcanoes. The analysis of Batchelor [1967] is based on a balance between viscous and gravitational forces acting on the film and involves the assumption that the falling film is thin compared with the pipe radius $\left(\lambda \ll r_{c}\right)$, yielding

$$
\lambda=\left(\frac{3 \eta r_{c} v_{s}}{2 \rho g}\right)^{\frac{1}{3}},
$$

This expression can also be derived from Brown [1965], under the assumption of a thin film. Equation (A2) can be written in terms of dimensionless quantities as

$$
\lambda^{\prime}=\left(6 \frac{F r}{N_{f}}\right)^{\frac{1}{3}}
$$

[72] Prediction of the film thickness from equations (A2) and (A3) require that the slug ascent velocity, or the Froude number, can be measured or estimated, respectively. James et al. [2008] measure ascent velocity directly for their experiments and find that the Batchelor [1967] model gives better agreement with their experimental observations than the Brown [1965] model. Consequently, they apply the Batchelor [1967] model to the volcanic case [James et al., 2008; 2009] and use an expression for $F r\left(N_{f}\right)$ from Wallis [1969]. We note that a more recent study [Viana et al., 2003] proposes an alternative expression for $F r\left(N_{f}\right)$ that is derived from an empirical fit to a much more extensive experimental data set. We recently developed a simplified form of this expression that is valid in the inertial-viscous regime [Llewellin et al., 2011]:

$$
F r=0.34\left[1+\left(\frac{31.08}{N_{f}}\right)^{1.45}\right]^{-0.71} .
$$

By combining equations (A3) and (A4) we have a second expression for $\lambda^{\prime}\left(N_{f}\right)$.

[73] Batchelor [1967] also presents a simplified version of equation (A2) predicated on the additional assumption of constant Froude number $\mathrm{Fr}=0.34$, giving

$$
\lambda^{\prime}=0.9\left(\frac{\eta^{2}}{\rho^{2} r_{c}^{3} g}\right)^{\frac{1}{6}}=\left(\frac{2.04}{N_{f}}\right)^{\frac{1}{3}} .
$$

This expression is used by Vergniolle et al. [2004] to estimate conduit diameter from acoustic measurements of slug burst during Strombolian activity at Shishaldin volcano (Alaska).

[74] Following our new model [Llewellin et al., 2011], we also include the model proposed by Kang et al. [2010], who perform numerical simulations in the range $10<N_{f}<450$ and propose an empirical fit to their data:

$$
\lambda^{\prime}=0.64 N_{f}^{-0.2} .
$$




\section{Appendix B}

[75] In this appendix we give a detailed, worked example of how to apply the models developed in section 3 to calculate parameters that are relevant to volcanic slugs. As a case study, we choose the following set of values, which are plausible for a basaltic volcano: magma viscosity $\eta=$ $1,000 \mathrm{~Pa} \mathrm{~s}$, magma density $\rho=2,600 \mathrm{~kg} / \mathrm{m}^{3}$; conduit radius $r_{c}=1.5 \mathrm{~m}$, slug gas volume at atmospheric pressure $V_{a}=100 \mathrm{~m}^{3}$. We also assume ambient pressure at the surface $P_{a}=10^{5} \mathrm{~Pa}$ and gravitational acceleration $g=9.81 \mathrm{~m} / \mathrm{s}^{2}$; different values can be chosen for these parameters if subaqueous, subglacial, or extraterrestrial volcanism is being investigated.

\section{B1. Step 1: Calculate Inverse Viscosity $N_{f}$ From Equation (22)}

[76] This is the key parameter that controls slug ascent and morphology before burst. As it is dimensionless, this parameter scales from laboratory experiments to natural slugs as long as surface tension is negligible (which it is for all terrestrial igneous volcanism, see section 4.5). $N_{f}=42.3$ for the given input parameter values. If the slug ascent velocity is required, it can be calculated via the Froude number $\mathrm{Fr}$ (equations (27) and (A4)); in this example, $\mathrm{Fr}=$ 0.24 and $v_{s}=1.3 \mathrm{~m} / \mathrm{s}$. From equation (26) is also possible to calculate slug Reynolds number $R e$ to facilitate comparison with other works that use that parameter $(R e=10.1)$.

\section{B2. Step 2: Calculate Dimensionless Film Cross Section $A^{\prime}$ From Equation (28)}

[77] In this example, $A^{\prime}=0.49$. From this parameter, film thickness $\lambda$ and slug radius $r_{c}$ are derived using equations (6) and (25) $\left(\lambda=0.43 \mathrm{~m} ; r_{s}=1.07 \mathrm{~m}\right)$. Film thickness exerts an important control on slug burst behavior and is also important when inverting geophysical signals, e.g., in acoustic calculations [Vergniolle et al., 2004].

\section{B3. Step 3: Calculate the Stability Index $\gamma$}

[78] First determine $V_{a}^{\prime}$ from equation (18) $\left(V_{a}^{\prime}=3.6\right)$. The stability index $\gamma$ can now be calculated using equation (20) (for the standard model, in which magma remains confined to the conduit, giving, in this example, $\gamma=3.4$ ) or equation (21) (for the overflow model, in which magma overflows from the conduit during the ascent and burst of the slug, giving, in this example, $\gamma=7.0$ ). This key quantity allows the stability of the slug, i.e., whether or not it bursts with an overpressure, to be assessed immediately, since slugs are unstable for $\gamma>1$. Steps 4 and 5 are only applicable if $\gamma>1$.

\section{B4. Step 4: Calculate the Dimensionless Burst Pressure $P^{\prime}{ }_{b}$ Using Equation (16)}

[79] This is the pressure within the slug at burst, normalized by the ambient pressure; hence, for subaerial eruptions on Earth, it is equal to burst pressure expressed in bars (for the standard model, $P_{b}=126,912 \mathrm{~Pa}, \sim 1.27$ bars; for the overflow model, $P_{b}=163,505 \mathrm{~Pa}, \sim 1.64$ bars). This is the main outcome of the model, having direct implications for geophysical and volcanological observations and interpretations, as well as hazard assessment.

\section{B5. Step 5: Calculate the Slug Length at Burst $L_{b}$}

[80] First, calculate the dimensionless equivalent slug length at atmospheric pressure $L_{a}^{\prime}$ via equation (19) $\left(L_{a}^{\prime}=\right.$ 7.04), then the dimensionless slug length at burst $L_{b}^{\prime}$ via equation (17) $\left(L_{b}^{\prime}=5.55\right.$ and $L_{b}^{\prime}=4.31$ for the standard and overflow models, respectively), finally multiply by the characteristic length $P_{a} / \rho g$ to obtain the slug length at burst ( $L_{b}=21.8 \mathrm{~m}$ and $L_{b}=16.9 \mathrm{~m}$, respectively).

[81] Determining the length of the slug at burst is critical so that the validity of the standard and overflow models can be assessed, since, by comparing $L_{b}$ with geophysical/volcanological information [e.g., Ripepe et al., 2002] for the depth of the free magma surface, one can judge whether the magma is likely to remain confined to the conduit during slug ascent and burst, or to overflow. In the present example, the short slug length means that either model may apply. If, instead, we choose $V_{a}=100,000 \mathrm{~m}^{3}$, we obtain bursting slug lengths of several hundred meters, which is sufficiently long that magma must overflow; hence, the standard model is inappropriate.

[82] The above methodology is implemented in Table S1, which is available in the auxiliary material. This provides the calculation steps for both the standard and the overflow models. In this spreadsheet, as above, the input parameters are magma density and viscosity, conduit radius, gravitational acceleration, slug volume, and ambient pressure, and the main outputs are slug pressure and length at burst and the depth at which the slug becomes unstable. We note that it is possible to use the system of equations developed in section 3 in other ways; for example, the slug volume may be calculated as an output parameter if the slug burst pressure can be measured or estimated in the field.

[83] Acknowledgments. This work was partly funded by the INGVDPC project V2 "Paroxysm" and by the Project FIRB-MIUR "Development of innovative technologies for the environmental protection from natural events." This research is part of ED Ph.D. project $(\mathrm{PhD}$ school in Geophysics, University of Bologna) funded by Istituto Nazionale di Geofisica e Vulcanologia. We are grateful to Associate Editor M. P. Ryan and to an anonymous reviewer for their careful reviews and helpful comments.

\section{References}

Aiuppa, A., M. Burton, T. Caltabiano, G. Giudice, S. Guerrieri, M. Liuzzo, F. Murè, and G. Salerno (2010), Unusually large magmatic $\mathrm{CO}_{2}$ gas emissions prior to a basaltic paroxysm, Geophys. Res. Lett., 37, L17303, doi:10.1029/2010GL043837.

Alatorre-Ibargüengoitia, M. A., B. Scheu, D. B. Dingwell, H. DelgadoGranados, and J. Taddeucci (2010), Energy consumption by magmatic fragmentation and pyroclast ejection during Vulcanian eruptions, Earth Planet. Sci. Lett., 291(1-4), 60-69, doi:10.1016/j.epsl.2009.12.051.

Allard, P. (2010), $\mathrm{A} \mathrm{CO}_{2}$-rich gas trigger of explosive paroxysms at Stromboli basaltic volcano, Italy, J. Volcanol. Geotherm. Res., 189(3-4), 363-374, doi:10.1016/j.jvolgeores.2009.11.018.

Allard, P., A. Aiuppa, M. Burton, T. Caltabiano, C. Federico, G. Salerno, and A. La Spina (2008), Crater gas emissions and the magma feeding system of Stromboli volcano, in Learning From Stromboli Volcano: Insights From the 2002-2003 Eruption, Geophys. Monogr. Ser., vol. 182, edited by S. Calvari et al., pp. 65-80, AGU, Washington, D. C., doi:10.1029/ $182 \mathrm{GM} 07$.

Anderson, A. T. (1995), $\mathrm{CO}_{2}$ and the eruptibility of picrite and komatiite, Lithos, 34, 19-25.

Andronico, D., A. Cristaldi, P. Del Carlo, and J. Taddeucci (2009), Shifting styles of basaltic explosive activity during the 2002-03 eruption of Mt. Etna, Italy, J. Volcanol. Geotherm. Res., 180(2-4), 110-122, doi:10.1016/j.jvolgeores.2008.07.026.

Barberi, F., M. Rosi, and A. Sodi (1993), Volcanic hazard assessment at Stromboli based on review of historical data, Acta Vulcanol., 3, 173-187. 
Barberi, F., L. Civetta, M. Rosi, and R. Scandone (2009), Chronology of the 2007 eruption of Stromboli and the activity of the Scientific Synthesis Group, J. Volcanol. Geotherm. Res., 182(3-4), 123-130, doi:10.1016/j. jvolgeores.2008.09.019.

Batchelor, G. K. (1967), An Introduction to Fluid Dynamics, Cambridge Univ. Press, Cambridge, U. K.

Bertagnini, A., N. Métrich, P. Landi, and M. Rosi (2003), Stromboli volcano (Aeolian Archipelago, Italy): An open window on the deep-feeding system of a steady state basaltic volcano, J. Geophys. Res., 108(B7), 2336, doi:10.1029/2002JB002146.

Bertagnini, A., N. Métrich, L. Francalanci, P. Landi, S. Tommasini, and S. Conticelli (2008), Volcanology and magma geochemistry of the present-day activity: Constraints on the feeding system, in The Stromboli Volcano: An Integrated Study of the 2002-2003 Eruption, Geophys. Monogr. Ser., vol. 182, edited by S. Calvari et al., pp. 19-37, AGU, Washington, D. C., doi:10.1029/182GM04.

Blackburn, E. A., L. Wilson, and R. S. J. Sparks (1976), Mechanisms and dynamics of Strombolian activity, J. Geol. Soc., 132, 429-440, doi:10.1144 gsjgs.132.4.0429

Bottinga, Y., and M. Javoy (1989), MORB degassing: Evolution of $\mathrm{CO}_{2}$, Earth Planet. Sci. Lett., 95, 215-225, doi:10.1016/0012-821X(89) 90098-8

Bottinga, Y., and M. Javoy (1990), MORB degassing: Bubble growth and ascent, Chem. Geol., 81, 255-270, doi:10.1016/0009-2541(90)90050-H.

Bottinga, Y., and M. Javoy (1991), The degassing of Hawaiian tholeiite, Bull. Volcanol., 53, 73-85, doi:10.1007/BF00265413.

Brown, R. A. S. (1965), The mechanics of large gas bubbles in tubes: I. Bubble velocities in stagnant liquids, Can. J. Chem. Eng., 43(5), 217-223, doi:10.1002/cjce.5450430501

Burton, M., P. Allard, F. Mure, and A. La Spina (2007a), Magmatic gas composition reveals the source depth of slug-driven Strombolian explosive activity, Science, 317(5835), 227-230, doi:10.1126/science.1141900.

Burton, M. R., H. M. Mader, and M. Polacci (2007b), The role of gas percolation in quiescent degassing of persistently active basaltic volcanoes, Earth Planet. Sci. Lett., 264(1-2), 46-60, doi:10.1016/j.eps1.2007b.08.028.

Calvari, S., L. Spampinato, A. Bonaccorso, C. Oppenheimer, E. Rivalta, and E. Boschi (2011), Lava effusion-A slow fuse for paroxysms at Stromboli volcano?, Earth Planet. Sci. Lett., 301, 317-323, doi:10.1016/ j.eps1.2010.11.015.

Chouet, B. (2003), Volcano seismology, Pure Appl. Geophys., 160(3), 739-788, doi:10.1007/PL00012556.

Chouet, B., N. Hamisevicz, and T. R. McGetchin (1974), Photoballistics of volcanic jet activity at Stromboli, Italy, J. Geophys. Res., 79(32), 4961-4976, doi:10.1029/JB079i032p04961

Chouet, B., P. Dawson, T. Ohminato, M. Martini, G. Saccorotti, F. Giudicepietro, G. De Luca, G. Milana, and R. Scarpa (2003), Source mechanisms of explosions at Stromboli Volcano, Italy, determined from moment tensor inversions of very long period data, J. Geophys. Res., 108(B1), 2019, doi:10.1029/2002JB001919.

Chouet, B. A., P. B. Dawson, and M. Martini (2008), Shallow-conduit dynamics at Stromboli Volcano, Italy, imaged from waveform inversions, in Fluid Motion in Volcanic Conduits: A Source of Seismic and Acoustic Signals, edited by S. J. Lane and J. S. Gilbert, Geol. Soc. Spec. Publ., 307 , 57-84, doi:10.1144/SP307.5.

Chouet, B. A., P. B. Dawson, M. James, and S. Lane (2010), Seismic source mechanism of degassing bursts at Kilauea: Results from waveform inversion in the 10-50 s band, J. Geophys. Res., 115, B09311, doi:10.1029/ 2009JB006661.

Cimarelli, C., F. Di Traglia, and J. Taddeucci (2010), Basaltic scoria textures from a zoned conduit as precursors to violent Strombolian activity, Geology, 38(5), 439-442, doi:10.1130/G30720.1.

Colò, L., M. Ripepe, D. R. Baker, and M. Polacci (2010), Magma vesiculation and infrasonic activity at Stromboli open conduit volcano, Earth Planet. Sci. Lett., 292, 274-280, doi:10.1016/j.eps1.2010.01.018.

Corder, S. B. (2008), The near-surface expansion of gas slugs: Insights into eruptive activity at low magma viscosity volcanoes, Ph.D. thesis, Lancaster Environ. Cent., Lancaster Univ., Lancaster, U. K.

D'Auria, L. (2006), Numerical modelling of gas slugs rising in basaltic volcanic conduits: Inferences on very-long-period event generation, paper presented at International Workshop: The Physics of Fluid Oscillations in Volcanic Systems I, Lancaster Univ., Lancaster, U. K.

De Lauro, E., S. De Martino, M. Falanga, and M. Palo (2009), Modelling the macroscopic behavior of Strombolian explosions at Erebus volcano, Phys. Earth Planet. Inter., 176(3-4), 174-186, doi:10.1016/j.pepi.2009.05.003.

Edmonds, M., and T. M. Gerlach (2007), Vapor segregation and loss in basaltic melts, Geology, 35(8), 751-754, doi:10.1130/G23464A.1.

Gerst, A., M. Hort, P. R. Kyle, and M. Voge (2008), 4D velocity of Strombolian eruptions and man-made explosions derived from multiple
Doppler radar instruments, J. Volcanol. Geotherm. Res., 177(3), 648660, doi:10.1016/j.jvolgeores.2008.05.022.

Harris, A., and M. Ripepe (2007a), Temperature and dynamics of degassing at Stromboli, J. Geophys. Res, 112, B03205, doi:10.1029/2006JB004393.

Harris, A., and M. Ripepe (2007b), Synergy of multiple geophysical approaches to unravel explosive eruption conduit and source dynamics-A case study from Stromboli, Chem. Erde Geochem., 67(1), 1-35, doi:10.1016/j.chemer.2007.01.003.

Houghton, B. F., and H. M. Gonnermann (2008), Basaltic explosive volcanism: Constraints from deposits and models, Chem. Erde Geochem, 68(2), 117-140, doi:10.1016/j.chemer.2008.04.002.

Hui, H., and Y. Zhang (2007), Toward a general viscosity equation for natural anhydrous and hydrous silicate melts, Geochim. Cosmochim. Acta, 71(2), 403-416, doi:10.1016/j.gca.2006.09.003.

Ishibashi, H. (2009), Non-Newtonian behavior of plagioclase-bearing basaltic magma: Subliquidus viscosity measurement of the 1707 basalt of Fuji volcano, J. Volcanol. Geotherm. Res., 181(1-2), 78-88, doi:10.1016/j.jvolgeores.2009.01.004

James, M. R., S. J. Lane, and B. Chouet (2004), Pressure changes associated with the ascent and bursting of gas slugs in liquid-filled vertical and inclined conduits, J. Volcanol. Geotherm. Res., 129(1-3), 61-82, doi:10.1016/S0377-0273(03)00232-4.

James, M. R., S. J. Lane, and B. A. Chouet (2006), Gas slug ascent through changes in conduit diameter: Laboratory insights into a volcano-seismic source process in low-viscosity magmas, J. Geophys. Res., 111, B05201, doi:10.1029/2005JB003718.

James, M. R., S. J. Lane, and S. B. Corder (2008), Modelling the rapid nearsurface expansion of gas slugs in low viscosity magmas, in Fluid Motion in Volcanic Conduits: A Source of Seismic and Acoustic Signals, edited by S. J. Lane and J. S. Gilbert, Geol. Soc. Spec. Publ, 307, 147-167, doi:10.1144/SP307.9.

James, M. R., S. J. Lane, L. Wilson, and S. B. Corder (2009), Degassing at low magma-viscosity volcanoes: Quantifying the transition between passive bubble-burst and Strombolian eruption, J. Volcanol. Geotherm. Res., 180(2-4), 81-88, doi:10.1016/j.jvolgeores.2008.09.002.

Jaupart, C., and S. Vergniolle (1988), Laboratory models of Hawaiian and Strombolian eruptions, Nature, 331(6151), 58-60, doi:10.1038/331058a0 Jaupart, C., and S. Vergniolle (1989), The generation and collapse of a foam layer at the roof of a basaltic magma chamber, J. Fluid Mech., 203, 347-380, doi:10.1017/S0022112089001497.

Jones, K. R., J. B. Johnson, R. Aster, P. R. Kyle, and W. C. McIntosh (2008), Infrasonic tracking of large bubble bursts and ash venting at Erebus Volcano, Antarctica, J. Volcanol. Geotherm. Res., 177(3), 661-672, doi:10.1016/j.jvolgeores.2008.02.001.

Kang, C. W., S. P. Quan, and J. Lou (2010), Numerical study of a Taylor bubble rising in stagnant liquids, Phys. Rev., 81, 066308

Landi, P., N. Métrich, A. Bertagnini, and M. Rosi (2004), Dynamics of magma mixing and degassing recorded in plagioclase at Strombol (Aeolian Archipelago, Italy), Contrib. Mineral. Petrol., 147(2), 213-227, doi:10.1007/s00410-004-0555-5.

Landi, P., E. Marchetti, S. La Felice, M. Ripepe, and M. Rosi (2011), Integrated petrochemical and geophysical data reveals thermal distribution of the feeding conduits at Stromboli volcano, Italy, Geophys. Res. Lett., 38 , L08305, doi:10.1029/2010GL046296.

Lautze, N. C., and B. F. Houghton (2005), Physical mingling of magma and complex eruption dynamics in the shallow conduit at Stromboli volcano, Italy, Geology, 33(5), 425-428, doi:10.1130/G21325.1.

Lautze, N. C., and B. F. Houghton (2007), Linking variable explosion style and magma textures during 2002 at Stromboli volcano, Italy, Bull. Volcanol., 69, 445-460, doi:10.1007/s00445-006-0086-1.

Llewellin, E. W., H. M. Mader, and S. D. R. Wilson (2002), The constitutive equation and flow dynamics of bubbly magmas, Geophys. Res. Lett. 29(24), 2170, doi:10.1029/2002GL015697.

Llewellin, E. W., E. Del Bello, J. Taddeucci, P. Scarlato, and S. J. Lane (2011), The thickness of the falling film of liquid around a Taylor bubble, Proc. R. Soc. A, doi:10.1098/rspa.2011.0476, in press.

McGetchin, T. R., and B. A. Chouet (1979), Energy budget of the volcano Stromboli, Italy, Geophys. Res. Lett., 6(4), 317-320, doi:10.1029 GL006i004p00317.

Métrich, N., A. Bertagnini, P. Landi, and M. Rosi (2001), Crystallization driven by decompression and water loss at Stromboli volcano (Aeolian Islands, Italy), J. Petrol., 42(8), 1471-1490, doi:10.1093/petrology/ 42.8.1471.

Métrich, N., A. Bertagnini, and A. Di Muro (2010), Conditions of magma storage, degassing and ascent at Stromboli: New insights into the volcano plumbing system with inferences on the eruptive dynamics, J. Petrol., 51(3), 603-626, doi:10.1093/petrology/egp083.

Misiti, V., F. Vetere, A. Mangiacapra, H. Behrens, A. Cavallo, P. Scarlato, and D. B. Dingwell (2009), Viscosity of high-K basalt from the 5th Apri 
2003 Stromboli paroxysmal explosion, Chem. Geol., 260(3-4), 278-285, doi:10.1016/j.chemgeo.2008.12.023.

Mori, T., and M. Burton (2009), Quantification of the gas mass emitted during single explosions on Stromboli with the $\mathrm{SO}_{2}$ imaging camera, J. Volcanol. Geotherm. Res., 188(4), 395-400, doi:10.1016/j.jvolgeores.2009. 10.005 .

Mueller, S., E. W. Llewellin, and H. M. Mader (2010), The rheology of suspensions of solid particles, Proc. R. Soc. A, 466, 1201-1228, doi:10.1098/rspa.2009.0445.

Mueller, S., E. W. Llewellin, and H. M. Mader (2011), The effect of particle shape on suspension viscosity and implications for magmatic flows, Geophys. Res. Lett., 38, L13316, doi:10.1029/2011GL047167.

Murase, T., and A. R. McBirney (1973), Properties of some common igneous rocks and their melts at high temperatures, Geol. Soc. Am. Bull., 84, 3563-3592, doi:10.1130/0016-7606(1973)84<3563:POSCIR $>2.0 . C O ; 2$.

Namiki, A., and M. Manga (2008), Transition between fragmentation and permeable outgassing of low viscosity magmas, J. Volcanol. Geotherm. Res., 169(1-2), 48-60, doi:10.1016/j.jvolgeores.2007.07.020.

Nogueira, S., M. L. Rietmuler, J. B. L. M. Campos, and A. M. F. R. Pinto (2006), Flow in the nose region and annular film around a Taylor bubble rising through vertical columns of stagnant and flowing Newtonian liquids, Chem. Eng. Sci., 61(2), 845-857, doi:10.1016/j.ces.2005.07.038.

O'Brien, G. S., and C. J. Bean (2008), Seismicity on volcanoes generated by gas slug ascent, Geophys. Res. Lett., 35, L16308, doi:10.1029/ 2008GL035001.

Parfitt, E. A. (2004), A discussion of the mechanisms of explosive basaltic eruptions, J. Volcanol. Geotherm. Res., 134(1-2), 77-107, doi:10.1016/j. jvolgeores.2004.01.002.

Parfitt, E. A., and L. Wilson (1995), Explosive volcanic-eruptions-9: The transition between Hawaiian-style lava fountaining and Strombolian explosive activity, Geophys. J. Int., 121(1), 226-232, doi:10.1111/ j.1365-246X.1995.tb03523.x.

Patrick, M. R., A. Harris, M. Ripepe, J. Dehn, D. A. Rothery, and S. Calvari (2007), Strombolian explosive styles and source conditions: Insights from thermal (FLIR) video, Bull. Volcanol., 69, 769-784, doi:10.1007/s00445006-0107-0

Pino, N. A., R. Moretti, P. Allard, and E. Boschi (2011), Seismic precursors of a basaltic paroxysmal explosion track deep gas accumulation and slug upraise, J. Geophys. Res., 116, B02312, doi:10.1029/2009JB000826.

Polacci, M., D. R. Baker, L. Mancini, S. Favretto, and R. J. Hill (2009), Vesiculation in magmas from Stromboli and implications for normal Strombolian activity and paroxysmal explosions in basaltic systems, J. Geophys. Res., 114, B01206, doi:10.1029/2008JB005672.

Ripepe, M., and E. Gordeev (1999), Gas bubble dynamics model for shallow volcanic tremor at Stromboli, J. Geophys. Res., 104(B5), 10,639-10,654, doi:10.1029/98JB02734.

Ripepe, M., and A. J. L. Harris (2008), Dynamics of the 5 April 2003 explosive paroxysm observed at Stromboli by a near-vent thermal, seismic and infrasonic array, Geophys. Res. Lett., 35, L07306, doi:10.1029/ 2007GL032533.

Ripepe, M., and E. Marchetti (2002), Array tracking of infrasonic sources at Stromboli volcano, Geophys. Res. Lett., 29(22), 2076, doi:10.1029/ 2002GL015452.

Ripepe, M., A. J. L. Harris, and R. Carniel (2002), Thermal, seismic and infrasonic evidences of variable degassing rates at Stromboli volcano, J. Volcanol. Geotherm. Res., 118(3-4), 285-297, doi:10.1016/S03770273(02)00298-6.

Rosi, M., A. Bertagnini, and P. Landi (2000), Onset of the persistent activity at Stromboli Volcano (Italy), Bull. Volcanol., 62(4-5), 294-300, doi: $10.1007 / \mathrm{s} 004450000098$.

Rosi, M., A. Bertagnini, A. J. L. Harris, L. Pioli, M. Pistolesi, and M. Ripepe (2006), A case history of paroxysmal explosion at Stromboli: Timing and dynamics of the April 5, 2003 event, Earth Planet. Sci. Lett., 243(3-4), 594-606, doi:10.1016/j.eps1.2006.01.035.

Sawyer, G. M., S. A. Carn, V. I. Tsanev, C. Oppenheimer, and M. Burton (2008), Investigation into magma degassing at Nyiragongo volcano, Democratic Republic of the Congo, Geochem. Geophys. Geosyst., 9, Q02017, doi:10.1029/2007GC001829.
Self, S., L. Wilson, and I. A. Nairn (1979), Vulcanian eruption mechanisms, Nature, 277(5696), 440-443, doi:10.1038/277440a0.

Seyfried, R., and A. Freundt (2000), Experiments on conduit flow and eruption behavior of basaltic volcanic eruptions, J. Geophys. Res., 105(B10), 23,727-23,740, doi:10.1029/2000JB900096.

Stein, D. J., and F. J. Spera (2002), Shear viscosity of rhyolite-vapor emulsions at magmatic temperatures by concentric cylinder rheometry, J. Volcanol. Geotherm. Res., 113(1-2), 243-258, doi:10.1016/S03770273(01)00260-8.

Taddeucci, J., M. Pompilio, and P. Scarlato (2004a), Conduit processes during the July August 2001 explosive activity of Mt. Etna (Italy) Inferences from glass chemistry and crystal size distribution of ash particles, J. Volcanol. Geotherm. Res., 137(1-3), 33-54, doi:10.1016/j. jvolgeores.2004.05.011

Taddeucci, J., O. Spieler, B. Kennedy, M. Pompilio, D. B. Dingwell, and P. Scarlato (2004b), Experimental and analytical modeling of basaltic ash explosions at Mount Etna, Italy, 2001, J. Geophys. Res., 109, B08203, doi:10.1029/2003JB002952.

Taddeucci, J., P. Scarlato, A. Capponi, E. Del Bello, C. Cimarelli, D. M. Palladino, and U. Kueppers (2012), High-speed imaging of Strombolian explosions: The ejection velocity of pyroclasts, Geophys. Res. Lett., 39 , L02301, doi:10.1029/2011GL050404.

Valentine, G. A., D. Krier, F. V. Perry, and G. Heiken (2005), Scoria cone construction mechanisms, Lathrop Wells volcano, southern Nevada, USA, Geology, 33(8), 629-632, doi:10.1130/G21459.1.

Vergniolle, S., and G. Brandeis (1994), Origin of the sound generated by Strombolian explosions, Geophys. Res. Lett., 21(18), 1959-1962, doi:10.1029/94GL01286

Vergniolle, S., and G. Brandeis (1996), Strombolian explosions: 1. A large bubble breaking at the surface of a lava column as a source of sound, J. Geophys. Res., 101(B9), 20,433-20,447, doi:10.1029/96JB01178.

Vergniolle, S., and C. Jaupart (1986), Separated two-phase flow and basaltic eruptions, J. Geophys. Res., 91(B12), 12,842-12,860, doi:10.1029/ JB091iB12p12842.

Vergniolle, S., and M. Ripepe (2008), From Strombolian explosions to fire fountains at Etna Volcano (Italy): What do we learn from acoustic measurements?, in Fluid Motions in Volcanic Conduits: A Source of Seismic and Acoustic Signals, edited by S. J. Lane and J. S. Gilbert, Geol. Soc. Spec. Publ., 307, 103-124, doi:10.1144/SP307.7.

Vergniolle, S., G. Brandeis, and J. C. Mareschal (1996), Strombolian explosions: 2. Eruption dynamics determined from acoustic measurements, J. Geophys. Res., 101(B9), 20,449-20,466, doi:10.1029/96JB01925.

Vergniolle, S., M. Boichu, and J. Caplan-Auerbach (2004), Acoustic measurements of the 1999 basaltic eruption of Shishaldin volcano, Alaska: 1. Origin of Strombolian activity, J. Volcanol. Geotherm. Res., 137(1-3), 109-134, doi:10.1016/j.jvolgeores.2004.05.003.

Viana, F., R. Pardo, R. Yanez, J. Trallero, and D. Joseph (2003), Universal correlation for the rise velocity of long gas bubbles in round pipes, J. Fluid Mech., 494, 379-398, doi:10.1017/S0022112003006165.

Vidal, V., M. Ripepe, T. Divoux, D. Legrand, J. C. Geminard, and F. Melo (2010), Dynamics of soap bubble bursting and its implications to volcano acoustics, Geophys. Res. Lett., 37, L07302, doi:10.1029/2009GL042360.

Vona, A., C. Romano, D. B. Dingwell, and D. Giordano (2011), The rheology of crystal-bearing basaltic magmas from Stromboli and Etna, Geochim. Cosmochim. Acta, 75, 3214-3236, doi:10.1016/j.gca.2011.03.031.

Wallis, G. B. (1969), One-Dimensional Two-Phase Flow, McGraw-Hill, New York.

Wilson, L. (1980), Relationships between pressure, volatile content and ejecta velocity, J. Volcanol. Geotherm. Res., 8, 297-313, doi:10.1016/ 0377-0273(80)90110-9.

E. Del Bello, P. Scarlato, and J. Taddeucci, Department of Seismology and Tectonophysics, Istituto Nazionale di Geofisica e Vulcanologia, Via di Vigna Murata 605, I-00143 Rome, Italy. (delbello@ingv.it)

S. J. Lane, Lancaster Environment Centre, Lancaster University, Lancaster LA1 4YQ, UK.

E. W. Llewellin, Department of Earth Sciences, Durham University, South Road, Durham DH1 3LE, UK. 